\title{
Preparation, Functional Characterization, and NMR Studies of Human KCNE1, a Voltage-Gated Potassium Channel Accessory Subunit Associated With Deafness and Long QT Syndrome ${ }^{\dagger}$
}

\author{
Changlin Tian $\ddagger, \S$, Carlos G. Vanoye ${ }^{\|}$, Congbao Kang ${ }^{\ddagger}$, Richard C. Welch ${ }^{\|}$, Hak Jun Kim $\ddagger$, \\ Alfred L. George Jr. $\|, \perp$, and Charles R. Sanders ${ }^{\star}, \neq$ \\ Department of Biochemistry, Center for Structural Biology, Department of Medicine and Department \\ of Pharmacology, Vanderbilt University School of Medicine, Nashville, TN, 37232-8725
}

\begin{abstract}
$\mathrm{KCNE}$, also known as minK, is a member of the KCNE family of membrane proteins that modulate the function of KCNQ1 and certain other voltage-gated potassium channels $\left(\mathrm{K}_{\mathrm{V}}\right)$. Mutations in human KCNE1 cause congenital deafness and congenital long QT syndrome, an inherited predisposition to potentially life-threatening cardiac arrhythmias. Although its modulation of KCNQ1 function has been extensively characterized, many questions remain regarding KCNE1's structure and location within the channel complex. In this study KCNE1 was overexpressed in $E$. coli and purified. Micellar solutions of the protein were then microinjected into Xenopus oocytes expressing KCNQ1 channels, followed by electrophysiological recordings to test whether recombinant KCNE1 can co-assemble with the channel. Native-like modulation of channel properties was observed following injection of KCNE1 in lysomyristoylphosphatidylglycerol (LMPG) micelles, indicating that KCNE1 is not irreversibly misfolded and that LMPG is able to act as a vehicle for delivering membrane proteins into the membranes of viable cells. ${ }^{1} \mathrm{H},{ }^{15} \mathrm{~N}$-TROSY NMR experiments indicated that LMPG micelles are well-suited for structural studies of KCNE1, leading to assignment of its backbone resonances and to relaxation studies. The chemical shift data confirmed that KCNE1's secondary structure includes several $\alpha$-helices and demonstrated that its distal Cterminus is disordered. Surprisingly, for KCNE1 in LMPG micelles there appears to be a break in $\alpha$-helicity at sites 59-61, near the middle of the transmembrane segment, a feature that is accompanied by increased local backbone mobility. Given that this segment overlaps with sites 57 -59 , which are known to play a critical role in modulating KCNQ1 channel activation kinetics, this unusual structural feature is likely of considerable functional relevance.
\end{abstract}

\footnotetext{
Voltage-gated potassium channels $\left(\mathrm{K}_{\mathrm{V}}\right)$ play a variety of important roles in human health and disease. For example, human KCNQ1 is essential to the cardiac action potential that mediates heartbeat and is also critical for potassium ion homeostasis in the inner ear( $1 ; 2)$. The function of several $\mathrm{K}_{\mathrm{V}}$ channels is modulated by accessory proteins including $\mathrm{K}_{\mathrm{V}}$ channel $\beta$ subunits $(\mathrm{Kv} \beta)(3-6)$, potassium channel interacting proteins $(\mathrm{KCHiP})(7 ; 8)$, and the $\mathrm{KCNE}$ family of

${ }^{\dagger}$ This study was supported by NIH grant R01 DC007416 to CRS, NIH grant HL077188 to ALG, a Vanderbilt School of Medicine Discovery Grant to CGV, and by a postdoctoral fellowship from the American Heart Association to CT (0625586B). Some data were collected in the SEC NMR facility at the University of Georgia, which is supported by US NIH grant P41 GM066340. The NMR assignments for KCNE1 that are reported in this paper have been deposited in the BMRB with access number 15102.

* To whom correspondence should be addressed: E-mail: chuck.sanders@ vanderbilt.edu; phone: 615-936-3756; fax: 615-936-2211.

\$Department of Biochemistry and Center for Structural Biology

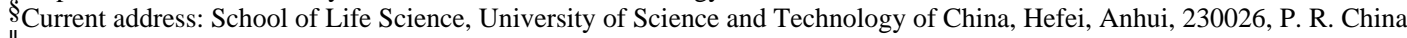

"Department of Medicine

$\perp_{\text {Department of Pharmacology }}$
} 
single transmembrane proteins including KCNE1 and minK-related peptides (MiRPs)(9-14). KCNE1, also known as minK, co-assembles with KCNQ1 in heart muscle cells to form a channel complex that generates the slowly activating cardiac potassium current $\left(\mathrm{I}_{\mathrm{Ks}}\right)$, an important determinant of myocardial repolarization $(9 ; 12 ; 14)$. KCNE1 alters several biophysical properties of KCNQ1 channels. The fully-activated whole-cell current is 4-6 times larger when KCNQ1 is complexed with KCNE1, the channel activation rate is reduced by more than an order of magnitude, and activation occurs at more positive potentials (9-14). The importance of KCNE1 in regulating KCNQ1 channel function is reflected by the fact that a number of inherited mutations in KCNE1 result in long QT syndrome (15-18), and deafness (19). Other members of the KCNE family can also modulate KCNQ1 function, each in an electrophysiologically distinct manner $(9 ; 12 ; 14 ; 20)$. For example, KCNE3 expression increases the magnitude of KCNQ1-mediated currents without slowing down channel activation(21). Moreover, KCNE family members have been shown to modulate other $\mathrm{K}_{\mathrm{v}}$ channels in addition to KCNQ1 $(9 ; 10 ; 12 ; 14 ; 19 ; 20 ; 22 ; 23)$.

Much is known about the structural basis for $\mathrm{K}_{\mathrm{v}}$ channel function thanks to the combined efforts of structural biology and decades of structure/function electrophysiological studies. However, much less is known regarding the structural biophysical basis for the regulation of KCNQ1 and other $\mathrm{K}_{\mathrm{v}}$ channels by the KCNE family of accessory subunits. Biochemical and mutagenesis/electrophysiological studies have led to predictions of proximity between certain sites in KCNE1 and KCNQ1(13;24-30). Accompanying these studies has been a lively debate regarding whether or not KCNE1 is actually located in the ion conduction pathway or instead modulates function by interacting with the outer (membrane-disposed) regions of the channel domain. Direct structural biophysical studies of KCNE1's interactions with $\mathrm{K}_{\mathrm{v}}$ channels have not yet been reported. Indeed, while there have been a number of NMR and other biophysical studies of polypeptide fragments of KCNE1(31-35), structural studies of the intact protein have not yet been reported. We have therefore initiated NMR structural studies of full length KCNE1 in model membranes (i.e., detergent micelles). The first stage of this work entailed bacterial expression of KCNE1 followed by purification.

E. coli has previously been used to overexpress many integral membrane proteins, including a number of ion channels, for use in biochemical and structural studies. Advantages of this approach include rapid cell growth, inexpensive media, capacity for uniform isotopic labeling, and the availability of divers cloning vectors. However, few human membrane proteins have been overexpressed in bacteria and even fewer have subsequently been shown to retain functionality. Moreover, while some classes of membrane proteins have functions that can readily be tested, this is very challenging for channel accessory subunits such as KCNE1, which lack intrinsic assayable functions. This problem is exacerbated when the experiments of interest will be carried out using detergent micelles as the model membrane medium. Micelles have been very commonly used to mimic the lipid membrane environment of membrane proteins in structural and functional studies, but cannot be employed in assays of channel function because of the lack of inside/outside aqueous compartmentalization in micelles. Moreover, not all detergents can maintain the native folded structure of any given membrane protein.

In this study we developed a high level E. coli-based overexpression system for human KCNE1 and purified the protein in a variety of types of micelles. To assess the degree to which the recombinant protein maintains a native-like structural state in the detergent solutions, aliquots were microinjected into Xenopus oocytes expressing human KCNQ1 channels to test whether the reconstituted KCNE1 can associate with and modulate the channels. Micellar systems that successfully sustained KCNE1 function were then tested for their potential as a medium for NMR-based structural studies. One detergent, LMPG, was found to be superior at both sustaining KCNE1 function and as a medium from which high quality solution NMR spectra of the protein can be obtained. NMR-based assessment of KCNE1's secondary structure and 
dynamics in LMPG micelles also provided results that were both surprising and, when correlated with available structure-function data available for KCNE1 modulation of the KCNQ1 channel, intriguing.

\section{MATERIALS AND METHODS}

\section{Cloning and Overexpression of Human KCNE1}

The cDNA for human KCNE1 was cloned into expression vector pET16b (Novagen Inc., La Jolla, CA) using the Seamless cloning approach (Stratagene, La Jolla, CA), which was based on use of polymerase chain reaction (PCR) with the Eam1104I enzyme only(36). Primers containing Eam 1 104I sites were used to amplify both the inserted KCNE1 gene and the pET16b vector, which provided directional cloning during subsequent ligation reactions. In the final construction, the Factor Xa protease cleavage site and associated spacer were removed during cloning and the full length KCNE1 gene was positioned immediately after a hexahistidine-tag $\left(\mathrm{His}_{6}\right.$ ) followed by a single glycine (Figure 1A). The construct was verified by sequencing.

Expression of the His 6 -tagged KCNE1 protein in the pET16b vector was under the control of an IPTG-inducible promoter. The expression construction was transformed into E. coli BL21 (DE3) CodonPlus-RP cells (Stratagene). Successful transformants were grown in M9 minimum media with $100 \mu \mathrm{g} / \mathrm{ml}$ ampicillin and $34 \mu \mathrm{g} / \mathrm{ml}$ chloramphenicol, and supplemented with a multi-vitamin (CVS Spectravite, 1/10 tablet per liter of medium). The culture was incubated at $37^{\circ} \mathrm{C}, 225 \mathrm{rpm}$, until $\mathrm{OD}_{600}=0.9$, at which point protein expression was induced using $1 \mathrm{mM} \mathrm{IPTG}$, followed by continued rotary shaking at $37^{\circ} \mathrm{C}$ for 8 hours.

\section{Purification of KCNE1 into Detergent Micelles}

Cells expressing recombinant KCNE1 were harvested by centrifugation at $4{ }^{\circ} \mathrm{C}$ and then suspended in $20 \mathrm{ml}$ lysis buffer ( $70 \mathrm{mM}$ Tris- $\mathrm{HCl}, 300 \mathrm{mM} \mathrm{NaCl}, \mathrm{pH}$ 8.0) per gram of wet cells, plus $2 \mathrm{mM} \beta$-mercaptoethanol (BME). The cell suspension was probe-sonicated (F550 sonic dismembrator, Misonix, Farmingdale, NY; power level $=6.0,5$ second pulses separated by 5 seconds) for 5 minutes on ice. The lysates were twice passed through an EmulsiFlex C3 high pressure homogenizer (Avestin, Ottawa, ON). Magnesium acetate (to $5 \mathrm{mM}$ ), DNase (to $0.02 \mathrm{mg} / \mathrm{ml}$ ), and RNase (to $0.02 \mathrm{mg} / \mathrm{ml}$ ) were then added and the lysate was rotated at $4^{\circ} \mathrm{C}$ for 2 hours. The lysate was centrifuged at $4{ }^{\circ} \mathrm{C}$ at $40,000 \mathrm{~g}$ for 20 minutes. The supernatant was discarded and the inclusion body pellet was washed/centrifuged twice using the same lysis buffer.

Inclusion bodies were suspended in binding buffer ( $20 \mathrm{mM}$ Tris, $100 \mathrm{mM} \mathrm{NaCl}, \mathrm{pH}$ 7.0, $8 \mathrm{M}$ Urea, $0.2 \%(\mathrm{w} / \mathrm{v}) \mathrm{SDS}$ ) and rotated at room temperature for 2 hours to dissolve the inclusion bodies, followed by centrifugation at room temperature at $40,000 \mathrm{~g}$ for 20 minutes to remove insoluble cell debris. The supernatant containing solubilized KCNE1 was incubated with $5 \mathrm{ml}$ of Ni(II)-NTA chromatographic resin (Superflow, Qiagen, Valencia, CA) per liter of original culture, which was rotated at room temperature for at least 30 minutes. The resin was then packed into a gravity-flow column and washed with 8 bed volumes of binding buffer. Impurities were eluted using a wash buffer $(20 \mathrm{mM}$ Tris- $\mathrm{HCl}, 100 \mathrm{mM} \mathrm{NaCl}, \mathrm{pH} 7.0,0.2 \%$ SDS, no urea, until $\mathrm{OD}_{280}$ returned to baseline. To exchange the detergent from SDS to a non-denaturing detergent, $10 \times 1$ column volumes of rinse buffer ( $20 \mathrm{mM}$ Tris-HCl, $100 \mathrm{mM} \mathrm{NaCl}, \mathrm{pH} 7.0)$ containing one of the following detergents: $0.5 \%$ OG, $0.5 \%$ DM, $0.5 \%$ DDM, $0.5 \%$ DPC, $0.2 \%, 0.5 \%$ DPC/SDS (10:1), PMAL-C12, $0.2 \%$ DTAB, 0.2\% LMPC/LMPG (4:1) or 0.2\% LMPG were used to re-equilibrate the column. KCNE1 was then eluted using a buffer containing the same detergent plus $250 \mathrm{mM}$ imidazole (analytical grade), $\mathrm{pH}$ 6.0. The $\mathrm{pH}$ of the solution after elution was tested and, if required, readjusted to 6.0 using acetic acid. All chromatographic buffers contained $2 \mathrm{mM} \mathrm{BME}$. The concentration of the purified protein was 
determined from the $\mathrm{OD}_{280}$ using an extinction coefficient of $1.2 \mathrm{mg} / \mathrm{ml}$ protein per $\mathrm{OD}_{280}$ unit in a $1 \mathrm{~cm}$ cell. The protein was confirmed as KCNE1 using proteolytic digestion and MALDI-based tandem mass-spectrometry (MS-MS) in the Vanderbilt Proteomics Core.

\section{Electrophysiological Functional Analysis of KCNQ1 and KCNE1}

cDNAs for KCNQ1 and KCNE1 were constructed in plasmid vectors pSP64T and pRc/CMV, respectively, as previously described (Tapper and George 2000). cRNA was then transcribed in vitro from EcoRI- (pSP64T-KCNQ1) or XbaI- (pRc/CMV-KCNE1) digested linear cDNA templates using Sp6 or T7 RNA polymerase and the mMessage mMachine transcription system (Ambion Inc, Austin, TX). The size and integrity of cRNA preparations were evaluated by formaldehyde-agarose gel electrophoresis, and full-length cRNA concentrations were estimated by comparison with a 0.24-9.5-kb RNA ladder (Sigma, St. Louis, MO).

Female Xenopus laevis were anesthetized by immersion in $0.2 \%$ tricaine for $15-30 \mathrm{~min}$. Ovarian lobes were removed and oocytes were manually defolliculated. Stage V-VI oocytes were injected with $25 \mathrm{nl}$ of cRNA (KCNQ1, $6 \mathrm{ng} /$ oocyte; KCNE1 constructs, $3 \mathrm{ng} /$ oocyte) and incubated at $18^{\circ} \mathrm{C}$ for $48-72$ hours in L-15, (Leibovitz's media, Invitrogen) diluted 1:1 with water and supplemented with penicillin $(150 \mu \mathrm{g} / \mathrm{ml})$ and streptomycin $(150 \mu \mathrm{g} / \mathrm{ml})$. Some oocytes were injected with $25 \mathrm{nl}$ water as controls for endogenous currents. Because previous studies revealed that Xenopus oocytes express an endogenous KCNE family gene(37), control currents from oocytes injected only with KCNQ1 cRNA were always recorded from each batch to test for possible channel modulation by endogenous KCNE subunits.

Currents were recorded at room temperature 2-3 days after injection using a twomicroelectrode voltage-clamp technique with an OC-725B amplifier (Warner Instruments Corp., Hamden, CT). Oocytes were bathed at room temperature $\left(22-25^{\circ} \mathrm{C}\right)$ in a modified ND96 solution containing (in $\mathrm{mM}$ ): $96 \mathrm{NaCl}, 4 \mathrm{KCl}, 2 \mathrm{MgCl}_{2}, 0.1 \mathrm{CaCl}_{2}, 5 \mathrm{HEPES}, \mathrm{pH} 7.6, \sim 200$ mosmol/kg. Data were recorded using Clampex 7 (Molecular Devices Corp., Sunnyvale, CA), filtered at $500 \mathrm{~Hz}$ and digitized at $2 \mathrm{kHz}$. Data were analyzed and plotted using a combination of Clampex, SigmaPlot 2000 (SPSS Science, Chicago, IL) and Origin 7.0 (OriginLab, Northampton, MA). Current-voltage and normalized isochronal voltage-activation relationships were obtained by measuring current for $2 \mathrm{~s}$ during depolarizing pulses between -50 and $+60 \mathrm{mV}$ from a holding potential of $-80 \mathrm{mV}$. The normalized isochronal data were fit with a Boltzmann function of the form: $1 /\left\{1+\exp \left[\left(\mathrm{V}-\mathrm{V}_{1 / 2}\right) / k_{\mathrm{v}}\right]\right\}$, where $\mathrm{V}_{1 / 2}$ is the halfmaximal activation voltage and $k_{\mathrm{v}}$ is the slope factor. Oocytes with currents at $-80 \mathrm{mV}$ (holding potential) larger than currents measured for water injected oocytes $(-0.15 \mu \mathrm{A})$ were considered leaky and not used for analysis.

\section{Injection of Micellar Solutions of $\mathrm{His}_{6}-\mathrm{KCNE} 1$ into Xenopus Oocytes and Electrophysiological Functional Analysis}

Functional analysis was performed as described above with the exception that oocytes were first injected with cRNA encoding KCNQ1 ( $25 \mathrm{nl}, 6 \mathrm{ng} /$ oocyte). This was followed 24 hours later by injection of $25 \mathrm{nl}$ of $0.8 \mathrm{mg} / \mathrm{ml} \mathrm{His}_{6}-\mathrm{KCNE}$ protein or protein-free detergent micelles. Whole-cell currents were measured 24 hours after injection of micellar solutions. An average oocyte volume is $700 \mathrm{~nL}(1.0-1.2 \mathrm{~mm}$ diameter). With injections of $25 \mathrm{~nL}$, all detergent solutions tested in this work were diluted to well below their nominal critical micelle concentrations. For example, the nearly 30 -fold dilution of a $0.1 \%$ LMPG solution leads to a final concentration of $75 \mu \mathrm{M}$, well below its reported critical micelle concentration of $0.2-0.3$ $\mathrm{mM}(38)$. It should also be noted that microinjection often transiently ruptures oocytes, which typically reseal to remain viable. Only viable oocytes were used for electrophysiological measurements. 
All experimental conditions were tested using oocytes from at least three frogs. Data are represented as mean \pm standard error, and in some figures error bars are smaller than the symbols. The numbers of experiments (oocytes) are provided in the figure legends.

\section{Sample Preparation and Two-Dimensional NMR Spectroscopy of KCNE1}

Purified $\mathrm{U}_{-}{ }^{15} \mathrm{~N}-\mathrm{His}_{6}$-KCNE1 was prepared in micellar solutions of one of following: $300 \mathrm{mM}$ DPC, $300 \mathrm{mM}$ DPC/SDS (molar ratio 10:1), $300 \mathrm{mM}$ SDS $150 \mathrm{mM}$ LMPC/LMPG (molar ratio 4:1), $300 \mathrm{mM}$ DPC, or $150 \mathrm{mM}$ LMPG. The DPS/SDS 10:1 and LMPC/LMPG 4:1 solutions were included because they represent zwitterionic/anionic detergent mixtures that mimic the ca. 10-20 mol\% anionic lipid composition of typical biological membranes.

To the eluted protein solution EDTA and DTT were added to $2 \mathrm{mM}$ and $\mathrm{D}_{2} \mathrm{O}$ was added to $10 \%(\mathrm{v} / \mathrm{v})$. The $\mathrm{pH}$ was adjusted to $\mathrm{pH} 6.0$ using acetic acid and then concentrated to a volume of $500 \mu \mathrm{l}$ using an Amicon Ultra-15 centrifugal filter device (10 kDa cut-off; Millipore, Bedford, MA). Samples were then transferred to $5 \mathrm{~mm}$ NMR tubes. The KCNE1 concentration was usually adjusted to $1.0 \mathrm{mM}$. KCNE1 had a tendency to form visible aggregates over a time scale of days upon incubation at higher concentrations and temperatures above room temperature. Solutions of $1 \mathrm{mM}$ KCNE1 in LMPG detergent micelles can be safely stored in $4^{\circ} \mathrm{C}$ for about $1-2$ months. For longer term storage, samples were frozen in liquid nitrogen, then stored in $-80^{\circ} \mathrm{C}$ freezer.

Two-dimensional ${ }^{1} \mathrm{H}^{-15} \mathrm{~N}$ correlation spectra of KCNE1 in different detergent micelles were acquired at $40^{\circ} \mathrm{C}$ using the Weigelt version of the TROSY pulse sequence(39) on a $600 \mathrm{MHz}$ Bruker spectrometer (Billerica, MA). $256 \times 1024$ complex points were acquired in the t 1 time domain $\left({ }^{15} \mathrm{~N}\right.$ dimension) and $\mathrm{t} 2$ time domain $\left({ }^{1} \mathrm{H}\right.$ dimension), respectively. The data were zerofilled to $512 \times 2048$ and apodized using a Gaussian window function prior to Fourier transformation using NMRPipe(40).

\section{Assignment of KCNE1's Backbone NMR Resonances}

Uniformly- ${ }^{2} \mathrm{H},{ }^{13} \mathrm{C},{ }^{15} \mathrm{~N}$-labeled KCNE1 was prepared in LMPG micelles at $1.0 \mathrm{mM}$ protein and $4 \%$ detergent concentration in a buffer containing $250 \mathrm{mM}$ imidazole, $2 \mathrm{mM}$ EDTA, 2 $\mathrm{mM}$ DTT, and $10 \% \mathrm{D}_{2} \mathrm{O}, \mathrm{pH}$ 6.0. NMR data was collected at $40^{\circ} \mathrm{C}$ on either a Varian Inova $900 \mathrm{MHz}$ spectrometer with a cryoprobe or a Bruker Avance $600 \mathrm{MHz}$ spectrometer using a conventional probe. Proton chemical shifts were referenced to internal DSS and ${ }^{13} \mathrm{C} /{ }^{15} \mathrm{~N}$ chemical shifts were referenced indirectly to DSS using absolute frequency ratios. The following series of 3D experiments were used for sequential resonance assignments: TROSYHNCO, TROSY-HNCA, TROSY-HN(CO)CA, TROSY-HNCACB and TROSY-HN(CO) $\mathrm{CACB}(41)$. To aid assignments, KCNE1 was also prepared in M9 medium that was supplemented with specific ${ }^{15} \mathrm{~N}$-amino acids ( $300 \mathrm{mg} / \mathrm{l} \mathrm{Tyr}, 150 \mathrm{mg} / \mathrm{l} \mathrm{Phe,} 300 \mathrm{mg} / \mathrm{l} \mathrm{Ile,} 300$ $\mathrm{mg} / \mathrm{l} \mathrm{Leu}, 300 \mathrm{mg} / \mathrm{l} \mathrm{Val}, 750 \mathrm{mg} / \mathrm{l}, 150 \mathrm{mg} / \mathrm{ml}$ Met, or $150 \mathrm{mg} / \mathrm{l} \mathrm{Cys}$ ) and an excess of all other amino acids in unlabeled form. The ensuing amino-acid-type-specific 2-D ${ }^{1} \mathrm{H},{ }^{15} \mathrm{~N}$-TROSY spectra were invaluable to resolving ambiguities in the preliminary resonance assignments that arose both from the modest spectral dispersion and from the relatively broad resonance linewidths observed for most peaks. Spectra were processed using NMRPipe(40) and analyzed using NMRView(42).

Attempts to assign KCNE1's side chain resonances using TOCSY-based NMR pulse sequences were not successful because of the unfavorable relaxation properties for the side chain resonances that results from the relatively large size (estimated at $60 \mathrm{kDa}$ ) of the KCNE1/ LMPG micellar complex. It is very possible that KCNE1 is a suitable candidate for application of "methyl-TROSY" labeling and related pulse sequence technology(43) to selectively assign the side chain methyl groups of Ile, Val, and Leu residues, but this has not yet been undertaken. 


\section{NMR Relaxation Experiments}

Uniformly ${ }^{2} \mathrm{H}$ and ${ }^{15} \mathrm{~N}$ labeled KCNE1 was prepared to $0.4 \mathrm{mM}$ in a buffer containing 250 mM imidazole, $\mathrm{pH}$ 6.0, 2 mM DTT, 2 mM EDTA and 10\% $\mathrm{D}_{2} \mathrm{O}$. TROSY-based 2-D pulse sequences were used for determination of $\mathrm{T}_{1}, \mathrm{~T}_{2}$, and ${ }^{1} \mathrm{H},{ }^{15} \mathrm{~N}$ steady-state $\operatorname{NOEs}(44)$. The relaxation experiments were performed at 600 and $800 \mathrm{MHz}$ and at $313^{\circ} \mathrm{K} . \mathrm{T}_{1}$ values were determined from a series of ${ }^{1} \mathrm{H}^{15} \mathrm{~N}$ correlation spectra with $100,200,400,800,1200,1600$, 2000 and $2400 \mathrm{~ms}$ relaxation evolution delays. The $\mathrm{T}_{2}$ values were obtained from the spectra with $6,18,30,54,78,114,150$ and $198 \mathrm{~ms}$ delays. The steady state ${ }^{1} \mathrm{H}_{-}{ }^{15} \mathrm{~N}$ NOE values were determined from peak ratios observed between two spectra, one collected with a $3 \mathrm{~s}$ presaturation of protons and the other without proton presaturation. The spectra were processed using NMRPipe and analyzed with NMRView.

\section{Results}

\section{Expression and Purification of Human KCNE1}

His $_{6}$-KCNE1 was overexpressed with an N-terminal purification tag (Figure 1A) into inclusion bodies using a strain of $E$. coli optimized for translation of mRNA containing rare codons. That $\mathrm{His}_{6}$-KCNE1 expressed into inclusion bodies in $E$. coli is not surprising given that mammalian membrane proteins often do not incorporate well into the plasma membrane of $E$. coli. Moreover, the fact that KCNE1's transmembrane domain is bounded on both ends by several positively-charged residues in both juxtamembrane segments dictates that insertion of this protein into the plasma membrane by the cellular insertion apparatus would not be expected because this would violate the "positive inside rule" that characterizes the topology of juxtamembrane Lys and Arg residues observed for most native membrane proteins of $E$. coli and many other organisms(45).

A flexible protocol was developed to purify KCNE1 into detergent micelles using Ni(II)-NTAbased metal ion chelate chromatography. Inclusion bodies were solubilized using $8 \mathrm{M}$ urea plus a harsh detergent, SDS, followed by binding to Ni(II)-metal ion affinity resin and elution of all impurities. On-resin refolding of KCNE1 was accomplished by re-equilibrating the column with a non-denaturing detergent solution (e.g., DDM or LMPG), followed by elution of pure protein in micelles of the same detergent. The yield of KCNE1 was observed to vary with the detergent employed at the final stages of purification, although the final protein was always observed to be of high purity (c.f., Figure 1B). Yields of pure protein (milligrams of pure KCNE1 per liter of culture) were $<<1$ (OG or DM), $<1$ (DDM), 1 (DTAB or PMAL-C12), 2 (DPC), 7 (LMPC:LMPG = 4:1), and 10 (SDS or LMPG). The different elution yields reflect the dependence of KCNE1 solubility on micellar environment, with anionic micelles clearly being preferred by KCNE1 over neutral detergents (OG, DM, DDM), zwitterionic detergents (DPC, LMPC), cationic detergents (DTAB), or zwitterionic amphipathic polymers - "amphipols" (PMAL-12). Cross-linking of purified KCNE1 in these mixtures using $20 \mathrm{mM}$ glutaraldehyde, followed by SDS-PAGE, indicated that KCNE1 in each of the three neutral detergents is highly prone to form high molecular weight aggregates, an observation that may explain the low purification yields observed for these detergents. These neutral detergent/ KCNE1 mixtures were not subjected to further characterization in this work.

\section{Functional Expression of Human $\mathrm{His}_{6}-\mathrm{KCNE}_{1}$ in Xenopus Oocytes}

To test whether the $\mathrm{His}_{6}$ tag interferes with KCNE1 native function, we compared modulation of KCNQ1 by tagged versus untagged KCNE1. For these tests, cRNA encoding either tagged or non-tagged KCNE1 was microinjected into oocytes along with cRNA encoding KCNQ1, followed by electrophysiological examination of channel properties. It was observed that both untagged and His $_{6}$-tagged KCNE1 led to dramatically-increased KCNQ1 conductance while also slowing the rate of current activation (Figure 2), which reflects the formation of a 
functional complex between KCNE1 and KCNQ1. Current-voltage relationships and normalized isochronal activation curves were observed to be very similar for tagged and nontagged KCNE1. Figure $2 \mathrm{C}$ illustrates normalized isochronal activation data fit with a Boltzmann distribution to obtain apparent $\mathrm{V}_{1 / 2}$ and slope $\left(k_{V}\right)$ factors. The calculated values for KCNQ1 and untagged KCNE1 are: $\mathrm{V}_{1 / 2}=28.1 \pm 1.5$ and $k_{V}=21.5 \pm 1.2$; while values for KCNQ1 and His $_{6}-$ KCNE1 were not significantly different: $\mathrm{V}_{1 / 2}=27.0 \pm 1.6$ and $k_{V}=23.6 \pm$ 1.2. The presence of a $\mathrm{His}_{6}$ tag does not affect the ability of KCNE1 to modulate KCNQ1.

\section{Microinjection of KCNE1 in Detergent Micelle Solutions into Xenopus Oocytes}

A concern regarding KCNE1 in detergent micelles is whether it is correctly folded or whether it might instead be irreversibly misfolded. Although KCNE1 has no known independent function, its integrity following purification and reconstitution can be determined by assessing its modulation of KCNQ1. We therefore injected purified His $_{6}$-KCNE1 into Xenopus oocytes expressing KCNQ1 channels. Figure 3 shows representative whole-cell currents recorded when KCNQ1-expressing oocytes were injected with recombinant KCNE1 in micelles (with dilution to well below the critical micelle concentration of the detergent). Injection of $\mathrm{His}_{6}-\mathrm{KCNE} 1$ from DPC (Fig.3A) and SDS (Fig.3B) micelles did not alter the function of KCNQ1 channels (see Figure 2A). Whether this lack of function was the result of irreversible misfolding of KCNE1 in SDS and DPC, or whether these detergents are simply unable to deliver and facilitate insertion of KCNE1 into oocyte membranes was not established by these results. In contrast, injection of $\mathrm{His}_{6}$-KCNE1 from PMAL-C12 (Fig. 3C), DTAB (Fig. 3D), LMPC/LMPG (4:1, Fig. 3E) or LMPG (Fig. 3F) solutions into oocytes altered KCNQ1 activity in a manner similar to His $_{6}$-KCNE1 expressed from cRNA (Fig. 2A): whole-cell current increased and current activation was delayed. While functional interaction of purified $\mathrm{His}_{6}$-KCNE1 with KCNQ1 $^{-}$ was also observed with LMPC/G, PMAL-C12 and DTAB, the highest increase in current magnitude and the most reduced rate of current activation were observed when His $_{6}$-KCNE1 was injected from LMPG micelles (Figure 3F). For all the compounds tested, injection of micelles devoid of protein did not alter KCNQ1 channel activity (data not shown). It should be noted that the number of dead or leaky oocytes (see Methods) was much higher following injection of SDS or DPC micelles ( \pm KCNE1) injection relative to LMPG, LMPC/G, PMAL$\mathrm{C} 12$, and DTAB.

\section{Viability of $\mathrm{His}_{6}-\mathrm{KCNE} 1$ in LMPG micelles}

Figure 4 shows representative whole-cell currents recorded from oocytes injected with cRNA for KCNQ1 (A) or cRNA for both KCNQ1 plus $\mathrm{His}_{6}$-KCNE1 (B, "positive control"). Injection of "empty" LMPG micelles did not affect the properties of KCNQ1 channels (Fig. 4C). In contrast, injection of purified His $_{6}$-KCNE1 in LMPG led to whole-cell currents (Fig. 4D) that resembled the current recorded from oocytes injected with cRNA for both KCNQ1 and $\mathrm{His}_{6^{-}}$ KCNE1 (Fig. 4B). The increase in the current amplitude (Fig. 4E) and voltage dependence of activation (Fig. 4F) were similar, whether cRNA for $\mathrm{His}_{6}-\mathrm{KCNE} 1$ or recombinant protein were injected. Collectively, these results demonstrated that recombinant $\mathrm{His}_{6}$-KCNE1 in LMPG micelles was not irreversibly misfolded and that micelles of this type were able to effectively deliver KCNE1 to oocyte membranes, where it then inserted and modulated KCNQ1 function in a native-like manner.

In contrast to the case for LMPG, the results for SDS and DPC fall short of validating the use these types of micelles as suitable media for structural studies of KCNE1. Results for the other systems tested--LMPC/LMPG, DTAB and PMAL-C12, indicated no cause for concern, although LMPG was observed be optimal. 


\section{D NMR Spectra of KCNE1 in Different Micelles}

Because KCNE1 is only weakly soluble in PMAL-C12 or DTAB, we did not attempt to acquire NMR spectra in these media, but focused instead on LMPG and on a 4:1 LMPC:LMPG mixture. For the sake of comparison, spectra were also acquired in SDS and DPC. $600 \mathrm{MHz}$ TROSY NMR spectra of the four samples are shown in Figure 5. While all 4 spectra were of reasonably high quality based on the number of peaks resolved, the spectra from LMPG and SDS are clearly superior, in each case yielding roughly 1 amide ${ }^{1} \mathrm{H},{ }^{15} \mathrm{~N}$-TROSY cross peaks for each residue of KCNE1. The spectrum for the LMPG sample was superior to that of SDS in that peak linewidths were much more uniform than for SDS. In the SDS case there are a number of low intensity (broad) peaks that can be observed only when the spectrum is plotted at a high vertical scale, as shown.

The combination of the fact that few peaks were observed at >8.9 PPM or <7.3 PPM in any of the 4 spectra and yet spectral quality was reasonably high in all cases suggests that KCNE1 is a mostly-helical protein under a broad range of micellar conditions.

\section{NMR Assignments and Dynamics of KCNE1 in LMPG Micelles}

Given the favorable oocyte injection results for KCNE1/LMPG and the particularly high quality of the TROSY NMR spectrum of the protein from this mixture, we proceeded to use a suite of 3D TROSY-based heteronuclear NMR experiments to assign the backbone resonances of uniformly-2 ${ }^{2},{ }^{13} \mathrm{C},{ }^{15} \mathrm{~N}$-labeled $\mathrm{His}_{6}$-KCNE1 in LMPG micelles. Ambiguities in assignment were clarified by labeling the protein with a series of specific ${ }^{15} \mathrm{~N}$-labeled amino acids (e.g., Cys, Met, Leu, Ile, Val, Trp or Phe) and then recording TROSY spectra for each sample. Nearly complete $\mathrm{H}(\mathrm{N}), \mathrm{N}, \mathrm{CO}$ and $\mathrm{C}_{\alpha}$ assignments (94\%), as well as $84 \%$ of $\mathrm{C}_{\beta}$ assignments were obtained and have been deposited in the BioMagResBank (www.bmrb.wisc.edu) with access number 15102. The assigned $900 \mathrm{MHz}{ }^{1} \mathrm{H},{ }^{15} \mathrm{~N}$-TROSY spectrum is shown in Figure 6. Preliminary TALOS analysis(46) of the chemical shifts led to determination of $\alpha$-helices spanning sites $9-23,46-58,62-69$, and $93-105$. This analysis is preliminary in the sense that chemical shift analysis is more reliable when $\mathrm{H}_{\alpha}$ chemical shifts are available, which they are not for KCNE1 (because backbone heteroatom assignments required the use of perdeuterated protein).

With assignments in-hand, we proceeded to collect a set of ${ }^{15} \mathrm{~N} \mathrm{~T}_{1}, \mathrm{~T}_{2}$, and steadystate ${ }^{1} \mathrm{H},{ }^{15} \mathrm{~N}$-NOE measurements at $600 \mathrm{MHz}$. These measurements are illustrated in Figure 7. The standard deviations associated with most points is considerable, reflecting both the modest signal-to-noise observed in spectra of KCNE1 and difficulties in resolving peaks in the 2-D relaxation data sets. To assess the reliability of the $600 \mathrm{MHz}$ measurements, we repeated relaxation experiments at $800 \mathrm{MHz}$ (Supplementary Figure 2). While the $800 \mathrm{MHz}$ measurements also exhibit considerable experimental uncertainties, there is generally good agreement with the $600 \mathrm{MHz}$ measurements of Figure 7.

From the $T_{1} / T_{2}$ ratio plateau for the transmembrane domain (residues 44-66) it is possible to calculate an overall correlation time for the KCNE1/LMPG complex of roughly $21 \mathrm{nsec}$, which is consistent with a protein/micelle aggregate molecular weight in the range of $60 \mathrm{kDa}$. The positive NOE values for residues 1-105 suggest that the N-terminus, transmembrane domain, and juxtamembrane C-terminus (67-105) contain considerable ordered structure, although both NOE and $\mathrm{T}_{1} / \mathrm{T}_{2}$ indicate significant local flexibility at a number of segments within this span, most obviously at sites spanning sites $1-10$ and $23-43$, but also including sites 58,59, and 61 in the transmembrane domain. Site 62 also exhibits unusual dynamics in that its amide $1 \mathrm{H}-15 \mathrm{~N}$ peak is undetectably broad, most likely due to intermediate timescale conformational exchange. The degree of order in the C-terminus of KCNE1 is seen to fall off starting after 
residue 105 , with mobility increasing as the extreme C-terminus is approached. This region of the protein appears to be largely disordered.

\section{Discussion}

\section{Microinjection of Recombinant KCNE1 into Xenopus Oocytes}

Previous studies have demonstrated the successful incorporation of membrane proteins into oocyte membranes following microinjection of solutions containing protein in membrane vesicles(47-49). In those studies the vesicles evidently either spontaneously fused with oocyte membranes or were actively engaged by the membrane fusion machinery of the cell. Here, is has been shown that is possible for a membrane protein to be successfully integrated into oocyte membranes following microinjection of the protein as a micellar solution. The exact routes taken by the injected KCNE1 to insert into the host oocyte membranes, the location of the organelle at which it co-assembles with the channel, and the membrane trafficking routes potentially taken by KCNE1 and KCNE1/KCNQ1 to reach the plasma membrane are being investigated. Based on the fact that some membrane proteins have the capacity to spontaneously insert into intact lipid vesicles when diluted from micelles, amphipols, or denaturant solutions (c.f.(50-52)), it is possible that insertion of KCNE1 into oocyte membranes may not require engagement with the cellular membrane protein insertion machinery.

In addition to using detergents to deliver KCNE1 to oocyte membranes, we also found that the zwitterionic amphipol PMAL-C12 was also an effective KCNE1 carrier. This represents the second report that amphipols can deliver an otherwise "naked" membrane protein into preformed lipid bilayers(51). Unlike detergents, amphipols will remain complexed with membrane proteins in aqueous solution even at very low concentrations and may therefore be especially appropriate membrane protein carrier agents for conditions where a purified membrane protein needs to be diluted many-fold into detergent-free solution $(53 ; 54)$. Amphipols have also been shown to be capable of sustaining the native functionality of membrane proteins $(53 ; 55 ; 56)$.

Recombinant KCNE1 was observed to attain its fully functional state in oocytes when it was injected from LMPG or, to a lesser degree, LMPC/LMPG (4:1), DTAB, or amphipol PMALC12 solutions, but not from DPC or SDS. There are two most-likely explanations for the latter observation. First, it is possible that KCNE1 was either terminally-misfolded in DPC or SDS, or was so destabilized in these micelle types that when it did bind to the native membranes it was in an "off-pathway" folding potential state, leading to misfolding. We cannot completely rule this out, but our NMR results (Figure 5) indicate that this is unlikely. The TROSY spectra of KCNE1 in SDS and DPC suggest that KCNE1 in these micelles is effectively structurally homogenous--if there are multiple conformations, they must be in rapid exchange with each other, not kinetically trapped in misfolded states (leading to extra sets of peaks or peak disappearances). Moreover, the NMR spectra from SDS and DPC bear some general similarity to the spectrum of KCNE1 in LMPG, for which more favorable functional results were obtained after microinjection. This suggests that the structure of KCNE1 in SDS or DPC bears some resemblance to that in LMPG.

An alternative explanation for why KCNE1 does not reach its functional state after microinjection from SDS or DPC solutions is that these detergents are unable to facilitate delivery and/or insertion of KCNE1 into oocyte membranes. One possibility is that when KCNE1 in DPC or SDS micelles is microinjected into oocytes that the detergent rapidly dissociates to monomer from KCNE1 as a consequence of dilution to below the CMC, leading to aggregation before the protein has a chance to reach the membrane in which in might otherwise insert. This explanation is unlikely. The CMCs for SDS (7 mM) and DPC (2 mM) are actually slightly lower than that of DTAB $(8 \mathrm{mM})(57)$, the latter of which was found to 
efficiently deliver KCNE1 to oocyte membranes. A more likely explanation for the failure of SDS and DPC to deliver is that LMPG, LMPC/LMPG, DTAB, and PMAL-C12 play active roles to facilitate correct membrane insertion of KCNE1, whereas SDS and DPC do not. Elucidation of the exact nature of the insertion mechanisms will require further study.

The ability to inject recombinant KCNE1 into oocytes from micellar solutions would appear to open the door to a host of applications, such as those that would exploit chemical tagging of KCNE1 prior to microinjection--experiments that are not feasible using standard molecular biological expression methods. However, choice of a suitable micellar solution is critical. Not all micellar solutions are well-tolerated by oocytes. Among the six detergents and amphipols examined herein, injection of SDS or DPC micelles caused a large number of oocytes to become irreversibly leaky (see Results). Recombinant KCNE1 in LMPC/G, PMAL-C12 and DTAB was observed to be able to co-assemble with the KCNQ1 channel. However, for these systems the degree of channel modulation by KCNE1 was lower than when LMPG was used, suggesting higher efficiency of co-assembly in the latter case.

In general, the results from the KCNE1 injection studies provide a modest degree of validation for the biological integrity of conducting structural studies of this protein in LMPG micelles, in micellar LMPC/LMPG mixtures, in DTAB micelles, or in amphipol PMAL-C12. On the other hand, for SDS and DPC the results can be regarded, at best, as being neutral on this question. Since KCNE1's solubility in DTAB and PMAL-C12 is only moderate, while being much higher in LMPG or LMPC/LMPG, the oocyte injection results lead to a modest preference for lyso-phospholipid micelles as the medium for structural studies of KCNE1. Lysophospholipids are increasingly being used as a medium for structural biological investigations of membrane proteins(58-62). Among all detergents, the lysophospholipids are the most phospholipid-like (except, perhaps, for the short chain diglyceride phospholipids). It is therefore not surprising that the lysophospholipids, including LMPG, been found to be exceptionally mild detergents in this work and in previous studies (60;63-66). This is in contrast to SDS, which denatures many proteins, including some (but not all) membrane proteins, whereas DPC is believed to be intermediate in the harsh-to-mild detergent scale (see review in(38)).

\section{Preliminary NMR Studies Provide Insight into KCNE1 Structure and Dynamics}

The fact that the spectra of the protein in LMPG and SDS are superior to spectra from DPC and 4:1 LMPC/LMPG suggests that there are intermediate time scale motions in these latter systems that result in severe line broadening for some resonances. However, all 4 spectra exhibit some general similarity (see Figure 5 and Supporting Figure 1), suggesting a degree of structural commonality for KCNE1 in these systems. LMPG was chosen as medium for ongoing structural studies of KCNE1 because it provides both an excellent NMR spectrum and because it performed admirably in the oocyte injection studies (above). LMPG has also previously been shown to be an extremely effective detergent at maintaining native-like structure and function in a complex membrane protein(66) and has also been shown to be useful as a medium for NMR studies of other membrane proteins $(58 ; 60 ; 67)$. That LMPG was observed to be nearly as effective as SDS at solubilizing KCNE1 (see Methods) is most likely due to the fact that it also has an anionic headgroup. However, LMPG is milder than SDS in terms of disrupting native protein structure, probably because it has a polar but uncharged spacer, glycerol, separating its apolar tail and charged headgroup.

The relatively narrow ${ }^{1} \mathrm{H},{ }^{15} \mathrm{~N}$ peak chemical shift dispersion observed for KCNE1 in LMPG micelles is characteristic of largely- $\alpha$-helical proteins. This modest chemical shift dispersion combined with the significant size of the KCNE1/LMPG micellar complex dictated that completion of assignments required use of very high magnetic fields, TROSY-based NMR pulse sequences(68), and supplementation of 3-D spectra with 2-D TROSY data from ${ }^{15} \mathrm{~N}$ - 
amino acid-specifically-labeled protein. Backbone NMR resonances assignments for KCNE1 in LMPG micelles were completed. TALOS-based analysis of the backbone chemical shifts confirms that at least 50 residues are part of $\alpha$-helices. The resonance assignments provide a basis for on-going efforts to determine the three-dimensional structure of KCNE1.

NMR relaxation measurements indicated that KCNE1's distal C-terminus (residues 106-129) is much more flexible than the rest of the protein and is largely disordered. This is not surprising since it has been shown that residues 94 and higher can be deleted from KCNE1 without disrupting its ability to modulate KCNQ1 $\mathrm{K}_{\mathrm{V}}$ channel function(29). It is, however, interesting to point out that this domain includes two known sites for mutations that result in long QT syndrome (Val109 and Pro127). We speculate that while the distal C-terminus is disordered under the conditions of our NMR studies and does not interact directly with KCNQ1, this very disorder makes this segment particularly accessible for participation in protein-protein interactions under cellular conditions. It was recently discovered that the cytosolic domain of KCNE1 interacts with a sarcomeric adaptor protein, T-cap (also know as telethonin), in a manner that may link KCNE1's modulation of KCNQ1 channel function to the protein assemblies involved in cardiac muscle contraction(69). While our results do not prove that the distal C-terminus of KCNE1 is crucial to interaction with T-cap, this domain would appear to be well-suited as a candidate for participation in such interactions.

In addition to revealing a mobile distal C-terminus, the NMR relaxation measurements suggest that residues 9-23, which comprise an $\alpha$-helix are nearly as immobile as most of the transmembrane domain (residues 44-66), which might reflect association of this segment with the micelle surface. This possibility is supported by a helical wheel plot (not shown), which indicates this segment is an amphipathic helix.

\section{The $\alpha$-Helicity of the Transmembrane Segment of KCNE1 in LMPG Micelles is Interrupted Near the Functionally-Critical Residues 57-59}

Previous studies of a polypeptide corresponding to the transmembrane segment of KCNE1 indicated that this polypeptide was largely $\alpha$-helical in a variety of different model membrane systems, unless conditions were such that the peptide aggregated, in which case aberrant $\beta$ sheet structure was observed (31-35). These previous studies included a careful NMR study that showed the isolated TM segment of KCNE1 in 86:14 hexafluoroisopropanol:water forms a single unbroken $\alpha$-helix(32). The results of this work are in general agreement with these previous observations in that we also observed that the majority of the KCNE1 transmembrane segment is helical. However, in contrast to the conclusions of the previous NMR study, our results for intact KCNE1 in LMPG micelles show that its TM helix is interrupted by a nonhelical mobile segment located roughly between sites 59-61. The variance of the results from these two studies most likely reflects the different model membrane media in which they were carried out. This begs the question of which system-LMPG micelles or a hexafluoroisopropanol/water mixture is closest to native-like conditions for KCNE1.

While we have argued that LMPG micelles represent an especially suitable membrane-mimetic medium, it should be considered that even lipid bilayers would not represent a truly nativelike environment for KCNE1 in its functionally relevant form. It is believed that KCNE1 associates with the KCNQ1 channel early in the secretory pathway and most likely remains stably associated with the channel(70;71). In this state, it is probable that one face of the KCNE1 transmembrane segment is lipid-exposed, but that the other face interacts with KCNQ1conditions that are impossible to ideally mimic for isolated KCNE1 in any model membrane system. We hypothesize that KCNE1's transmembrane segment has a propensity for being completely helical, but that that sites 59-61 have much a lower helical propensity than the rest of the segment. As a consequence, under some conditions (such as in LMPG micelles) it adopts a non-helical conformation. While a break in a TM helix might normally be regarded as 
energetically abhorrent because of the loss of backbone amide hydrogen bonding in a highly apolar environment, this is less of a problem in detergent micelles, which are much more watersaturated than lipid bilayers. Local loss of helicity for KCNE1 in its native complex with KCNQ1 would also be energetically feasible under native conditions if loss of classical helical backbone hydrogen bonds were compensated for by a rearrangement of hydrogen bonding partners within KCNE1 or through formation of favorable KCNQ1-KCNE1 interactions that satisfied KCNE1's hydrogen-bonding potential around sites 59-61.

It is not structurally obvious why the 59-61 segment has the unusual property of having only moderate helical propensity in a hydrophobic environment. The presence of a number of betabranched amino acids combined with two Gly residues in or near this segment may be a contributing factor. Another contributing factor in the highly dynamic and internallypermeable environment of micelles is that the side chain hydroxyl of Thr58 might transiently hydrogen bond either with water, with backbone amide groups within the adjacent non-helical segments, or with oxygen present in the glycerol/headgroup regions of LMPG.

Because the non-helical 59-61 segment of KCNE1 overlaps with sites 57-59, which are believed to be critical to modulation of KCNQ1 channel function, it is possible that the distinctive conformational and dynamic properties of this segment may be of the highest functional relevance. Sites 57-59 of KCNE1 are essential in defining how KCNE1 regulates channel function in manner that is distinct from other KCNE family members(13;25-27). It is believed that this segment interacts directly with the S6 segment of the pore domain, with Thr58 being especially important. Swapping these three sites out of KCNE1 for the corresponding sites in KCNE3 converts the triple-mutant-KCNE1 into a KCNE3-like modulator of KCNQ1 function(25). Namely, while channel conductance is dramatically increased by the presence of this triple mutant form of KCNE1 (just as for wild type), the delay in voltage-stimulated channel activation that is normally imposed by wild type KCNE1 is completely absent. This matches what is observed when bona fide KCNE3 serves as the $\beta$-subunit(21). Further elucidation of how the local dynamics near site 59 is related to modulation of KCNQ1 by KCNE1 will await completion of KCNE1's complete structure. However, the results of this work suggest that this segment may be able to interact with the transmembrane domain of the channel via an alterative mode to classical helix-helix interactions. The fact that this segment of KCNE1 also can access both helical and non-helical conformations, depending on the details of its non-polar medium, also suggests the feasibility that as the KCNQ1 channel undergoes transitions between open and closed conformational states, that the TM domain of KCNE1 could also undergo changes in conformation centered in the vicinity of residue 59.

\section{Acknowledgements}

The authors thank Dr. Fang Tian of the University of Georgia for collecting the $900 \mathrm{MHz}$ NMR data, Arina Hadziselimovic for help with molecular biology, Prof. Frank Sönnichsen for helpful discussion, and Markus Voehler and Dr. Murthy Karra for NMR technical assistance.

\section{Abbreviations}

BME, $\beta$-mercaptoethanol

CMC, critical micelle concentration

DDM, $\beta$-dodecylmaltoside

DM, $\beta$-decylmaltoside

DPC, dodecylphosphocholine

DSS, 2,2-dimethyl-2-silapentane-5-sulfonate

DTAB, dodecyltrimethylammonium bromide

IPTG, isopropylthiogalactoside

$\mathrm{K}_{\mathrm{V}}$, voltage-gated potassium channel 
LMPC, lysomyristoylphosphatidylcholine

LMPG, lysomyristoylphosphatidylglycerol

NMR, nuclear magnetic resonance

NOE, nuclear Overhauser effect

$\mathrm{OD}_{280}$, optical density at $280 \mathrm{~nm}$ for a sample with a $1 \mathrm{~cm}$ pathlength

OG, $\beta$-octylglucoside

PMAL-C12, zwitterionic amphipathic polymer prepared by stoichiometric substitution

(amidation with carboxylate generation) of the anhydride groups in poly(maleic anhydride-

alt-1-tetradecene) with 3-(dimethylamino)propylamine

QT, the QT interval is a phenomenological parameter that is extracted from electrocardiogram recordings that are used to monitor cardiac function in clinical settings

SDS, sodium dodecylsulfate

$\mathrm{T}_{1}$, longitudinal NMR relaxation time

$\mathrm{T}_{2}$, transverse NMR relaxation time

TM, transmembrane

TROSY, transverse relaxation optimized spectroscopy.

\section{References}

1. Jespersen T, Grunnet M, Olesen SP. The KCNQ1 potassium channel: from gene to physiological function. Physiology. (Bethesda. ) 2005;20:408-416. [PubMed: 16287990]

2. Robbins J. KCNQ potassium channels: physiology, pathophysiology, and pharmacology. Pharmacol. Ther 2001;90:1-19. [PubMed: 11448722]

3. Martens JR, Kwak YG, Tamkun MM. Modulation of Kv channel alpha/beta subunit interactions. Trends Cardiovasc. Med 1999;9:253-258. [PubMed: 11094335]

4. Pongs O, Leicher T, Berger M, Roeper J, Bahring R, Wray D, Giese KP, Silva AJ, Storm JF. Functional and molecular aspects of voltage-gated $\mathrm{K}+$ channel beta subunits. Molecular and Functional Diversity of Ion Channels and Receptors 1999;868:344-355.

5. Rettig J, Heinemann SH, Wunder F, Lorra C, Parcej DN, Dolly JO, Pongs O. Inactivation properties of voltage-gated K+ channels altered by presence of beta-subunit. Nature 1994;369:289-294. [PubMed: 8183366]

6. Trimmer JS. Regulation of ion channel expression by cytoplasmic subunits. Current Opinion in Neurobiology 1998;8:370-374. [PubMed: 9687351]

7. An WF, Bowlby MR, Betty M, Cao J, Ling HP, Mendoza G, Hinson JW, Mattsson KI, Strassle BW, Trimmer JS, Rhodes KJ. Modulation of A-type potassium channels by a family of calcium sensors. Nature 2000;403:553-556. [PubMed: 10676964]

8. Pourrier M, Schram G, Nattel S. Properties, expression and potential roles of cardiac K+ channel accessory subunits: MinK, MiRPs, KChIP, and KChAP. J. Membr. Biol 2003;194:141-152. [PubMed: 14502427]

9. McCrossan ZA, Abbott GW. The MinK-related peptides. Neuropharmacology 2004;47:787-821. [PubMed: 15527815]

10. Abbott GW, Sesti F, Splawski I, Buck ME, Lehmann MH, Timothy KW, Keating MT, Goldstein SA. MiRP1 forms IKr potassium channels with HERG and is associated with cardiac arrhythmia. Cell 1999;97:175-187. [PubMed: 10219239]

11. Abbott GW, Goldstein SAN, Sesti F. Do all voltage-gated potassium channels use MiRPs? Circulation Research 2001;88:981-983. [PubMed: 11375265]

12. Barhanin J, Lesage F, Guillemare E, Fink M, Lazdunski M, Romey G. K(V)LQT1 and lsK (minK) proteins associate to form the I(Ks) cardiac potassium current. Nature 1996;384:78-80. [PubMed: 8900282]

13. Melman YF, Krumerman A, McDonald TV. A single transmembrane site in the KCNE-encoded proteins controls the specificity of KvLQT1 channel gating. J. Biol. Chem 2002;277:25187-25194. [PubMed: 11994278] 
14. Sanguinetti MC, Curran ME, Zou A, Shen J, Spector PS, Atkinson DL, Keating MT. Coassembly of K(V)LQT1 and minK (IsK) proteins to form cardiac I(Ks) potassium channel. Nature 1996;384:8083. [PubMed: 8900283]

15. Napolitano C, Priori SG, Schwartz PJ, Bloise R, Ronchetti E, Nastoli J, Bottelli G, Cerrone M, Leonardi S. Genetic testing in the long QT syndrome: development and validation of an efficient approach to genotyping in clinical practice. JAMA 2005;294:2975-2980. [PubMed: 16414944]

16. Abbott GW, Goldstein SA. Disease-associated mutations in KCNE potassium channel subunits (MiRPs) reveal promiscuous disruption of multiple currents and conservation of mechanism. FASEB J 2002;16:390-400. [PubMed: 11874988]

17. Splawski I, Tristani-Firouzi M, Lehmann MH, Sanguinetti MC, Keating MT. Mutations in the hminK gene cause long QT syndrome and suppress IKs function. Nat. Genet 1997;17:338-340. [PubMed: 9354802]

18. Wang Q, Curran ME, Splawski I, Burn TC, Millholland JM, VanRaay TJ, Shen J, Timothy KW, Vincent GM, de Jager T, Schwartz PJ, Toubin JA, Moss AJ, Atkinson DL, Landes GM, Connors TD, Keating MT. Positional cloning of a novel potassium channel gene: KVLQT1 mutations cause cardiac arrhythmias. Nat. Genet 1996;12:17-23. [PubMed: 8528244]

19. Abbott GW, Goldstein SA. Potassium channel subunits encoded by the KCNE gene family: physiology and pathophysiology of the MinK-related peptides (MiRPs). Mol. Interv 2001;1:95-107. [PubMed: 14993329]

20. Tinel N, Diochot S, Lauritzen I, Barhanin J, Lazdunski M, Borsotto M. M-type KCNQ2-KCNQ3 potassium channels are modulated by the KCNE2 subunit. Febs Letters 2000;480:137-141. [PubMed: 11034315]

21. Schroeder BC, Waldegger S, Fehr S, Bleich M, Warth R, Greger R, Jentsch TJ. A constitutively open potassium channel formed by KCNQ1 and KCNE3. Nature 2000;403:196-199. [PubMed: 10646604]

22. McCrossan ZA, Lewis A, Panaghie G, Jordan PN, Christini DJ, Lerner DJ, Abbott GW. MinK-related peptide 2 modulates Kv2.1 and Kv3.1 potassium channels in mammalian brain. Journal of Neuroscience 2003;23:8077-8091. [PubMed: 12954870]

23. McDonald TV, Yu Z, Ming Z, Palma E, Meyers MB, Wang KW, Goldstein SA, Fishman GI. A minKHERG complex regulates the cardiac potassium current I(Kr). Nature 1997;388:289-292. [PubMed: 9230439]

24. Chen H, Kim LA, Rajan S, Xu S, Goldstein SA. Charybdotoxin binding in the I(Ks) pore demonstrates two MinK subunits in each channel complex. Neuron 2003;40:15-23. [PubMed: 14527430]

25. Melman YF, Domenech A, de la LS, McDonald TV. Structural determinants of KvLQT1 control by the KCNE family of proteins. J. Biol. Chem 2001;276:6439-6444. [PubMed: 11104781]

26. Melman YF, Um SY, Krumerman A, Kagan A, McDonald TV. KCNE1 binds to the KCNQ1 pore to regulate potassium channel activity. Neuron 2004;42:927-937. [PubMed: 15207237]

27. Panaghie G, Tai KK, Abbott GW. Interaction of KCNE subunits with the KCNQ1 K+ channel pore. J. Physiol 2006;570:455-467. [PubMed: 16308347]

28. Romey G, Attali B, Chouabe C, Abitbol I, Guillemare E, Barhanin J, Lazdunski M. Molecular mechanism and functional significance of the MinK control of the KvLQT1 channel activity. J. Biol. Chem 1997;272:16713-16716. [PubMed: 9201970]

29. Tapper AR, George AL Jr. MinK subdomains that mediate modulation of and association with KvLQT1. J. Gen. Physiol 2000;116:379-390. [PubMed: 10962015]

30. Tapper AR, George AL Jr. Location and orientation of minK within the $\mathrm{I}(\mathrm{Ks})$ potassium channel complex. J. Biol. Chem 2001;276:38249-38254. [PubMed: 11479291]

31. Aggeli A, Boden N, Cheng YL, Findlay JB, Knowles PF, Kovatchev P, Turnbull PJ. Peptides modeled on the transmembrane region of the slow voltage-gated IsK potassium channel: structural characterization of peptide assemblies in the beta-strand conformation. Biochemistry 1996;35:16213-16221. [PubMed: 8973194]

32. Aggeli A, Bannister ML, Bell M, Boden N, Findlay JB, Hunter M, Knowles PF, Yang JC. Conformation and ion-channeling activity of a 27-residue peptide modeled on the singletransmembrane segment of the IsK (minK) protein. Biochemistry 1998;37:8121-8131. [PubMed: 9609707] 
33. Ben Efraim I, Bach D, Shai Y. Spectroscopic and functional characterization of the putative transmembrane segment of the minK potassium channel. Biochemistry 1993:2371-2377. [PubMed: 8443177]

34. Horvath LI, Knowles PF, Kovachev P, Findlay JB, Marsh D. A single-residue deletion alters the lipid selectivity of a K+ channel- associated peptide in the beta-conformation: spin label electron spin resonance studies. Biophys. J 1997;73:2588-2594. [PubMed: 9370453]

35. Mercer EA, Abbott GW, Brazier SP, Ramesh B, Haris PI, Srai SK. Synthetic putative transmembrane region of minimal potassium channel protein (minK) adopts an alpha-helical conformation in phospholipid membranes. Biochem. J 1997;325(Pt 2):475-479. [PubMed: 9230130]

36. Korepanova A, Gao FP, Hua Y, Qin H, Nakamoto RK, Cross TA. Cloning and expression of multiple integral membrane proteins from Mycobacterium tuberculosis in Escherichia coli. Protein Sci 2005;14:148-158. [PubMed: 15608119]

37. Anantharam A, Lewis A, Panaghie G, Gordon E, McCrossan ZA, Lerner DJ, Abbott GW. RNA interference reveals that endogenous Xenopus MinK-related peptides govern mammalian K+ channel function in oocyte expression studies. Journal of Biological Chemistry 2003;278:11739-11745. [PubMed: 12529362]

38. Sanders CR, Sonnichsen F. Solution NMR of membrane proteins: practice and challenges. Magn Reson. Chem 2006;44:S24-S40. [PubMed: 16826539]Spec No

39. Weigelt J. Single scan, sensitivity- and gradient-enhanced TROSY for multidimensional NMR experiments. Journal of the American Chemical Society 1998;120:10778-10779.

40. Delaglio F, Grzesiek S, Vuister GW, Zhu G, Pfeifer J, Bax A. NMRPipe: a multidimensional spectral processing system based on UNIX pipes. J. Biomol. NMR 1995;6:277-293. [PubMed: 8520220]

41. Salzmann M, Pervushin K, Wider G, Senn H, Wuthrich K. TROSY in triple-resonance experiments: new perspectives for sequential NMR assignment of large proteins. Proc. Natl. Acad. Sci. U. S. A 1998;95:13585-13590. [PubMed: 9811843]

42. Johnson BA. Using NMRView to visualize and analyze the NMR spectra of macromolecules. Methods Mol. Biol 2004;278:313-352. [PubMed: 15318002]

43. Tugarinov V, Hwang PM, Kay LE. Nuclear magnetic resonance spectroscopy of high-molecularweight proteins. Annu. Rev. Biochem 2004;73:107-146. [PubMed: 15189138]

44. Zhu G, Xia Y, Nicholson LK, Sze KH. Protein dynamics measurements by TROSY-based NMR experiments. J. Magn Reson 2000;143:423-426. [PubMed: 10729271]

45. Nilsson J, Persson B, von HG. Comparative analysis of amino acid distributions in integral membrane proteins from 107 genomes. Proteins 2005;60:606-616. [PubMed: 16028222]

46. Cornilescu G, Delaglio F, Bax A. Protein backbone angle restraints from searching a database for chemical shift and sequence homology. J. Biomol. NMR 1999;13:289-302. [PubMed: 10212987]

47. Le CF, Bron P, Verbavatz JM, Garret A, Morel G, Cavalier A, Bonnec G, Thomas D, Gouranton J, Hubert JF. Incorporation of proteins into (Xenopus) oocytes by proteoliposome microinjection: functional characterization of a novel aquaporin. J. Cell Sci 1996;109(Pt 6):1285-1295. [PubMed: 8799818]

48. Marsal J, Tigyi G, Miledi R. Incorporation of acetylcholine receptors and Cl- channels in Xenopus oocytes injected with Torpedo electroplaque membranes. Proc. Natl. Acad. Sci. U. S. A 1995;92:5224-5228. [PubMed: 7761478]

49. Miledi R, Eusebi F, Martinez-Torres A, Palma E, Trettel F. Expression of functional neurotransmitter receptors in Xenopus oocytes after injection of human brain membranes. Proc. Natl. Acad. Sci. U. S. A 2002;99:13238-13242. [PubMed: 12237406]

50. Mi D, Kim HJ, Hadziselimovic A, Sanders CR. Irreversible misfolding of diacylglycerol kinase is independent of aggregation and occurs prior to trimerization and membrane association. Biochemistry 2006;45:10072-10084. [PubMed: 16906765]

51. Nagy JK, Kuhn HA, Keyes MH, Gray DN, Oxenoid K, Sanders CR. Use of amphipathic polymers to deliver a membrane protein to lipid bilayers. FEBS Lett 2001;501:115-120. [PubMed: 11470268]

52. Nagy JK, Lonzer WL, Sanders CR. Kinetic study of folding and misfolding of diacylglycerol kinase in model membranes. Biochemistry 2001;40:8971-8980. [PubMed: 11467959]

53. Popot JL, Berry EA, Charvolin D, Creuzenet C, Ebel C, Engelman DM, Flotenmeyer M, Giusti F, Gohon Y, Hong Q, Lakey JH, Leonard K, Shuman HA, Timmins P, Warschawski DE, Zito F, 
Zoonens M, Pucci B, Tribet C. Amphipols: polymeric surfactants for membrane biology research. Cell Mol. Life Sci 2003;60:1559-1574. [PubMed: 14513831]

54. Sanders CR, Kuhn HA, Gray DN, Keyes MH, Ellis CD. French swimwear for membrane proteins. Chembiochem 2004;5:423-426. [PubMed: 15185363]

55. Gorzelle BM, Hoffman AK, Keyes MH, Gray DN, Ray DG, Sanders CR. Amphipols can support the activity of a membrane enzyme. J. Am. Chem. Soc 2002;124:11594-11595. [PubMed: 12296714]

56. Pocanschi CL, Dahmane T, Gohon Y, Rappaport F, Apell HJ, Kleinschmidt JH, Popot JL. Amphipathic polymers: tools to fold integral membrane proteins to their active form. Biochemistry 2006;45:13954-13961. [PubMed: 17115690]

57. Beyer K, Leine D, Blume A. The demicellization of alkyltrimethylammonium bromides in $0.1 \mathrm{M}$ sodium chloride solution studied by isothermal titration calorimetry. Colloids Surf. B Biointerfaces 2006;49:31-39. [PubMed: 16580819]

58. Duchardt E, Sigalov AB, Aivazian D, Stern LJ, Schwalbe H. Structure Induction of the T-Cell Receptor zeta-Chain upon Lipid Binding Investigated by NMR Spectroscopy. Chembiochem. 2007

59. Klammt C, Schwarz D, Eifler N, Engel A, Piehler J, Haase W, Hahn S, Dotsch V, Bernhard F. Cellfree production of $\mathrm{G}$ protein-coupled receptors for functional and structural studies. J. Struct. Biol. 2007

60. Krueger-Koplin RD, Sorgen PL, Krueger-Koplin ST, Rivera-Torres IO, Cahill SM, Hicks DB, Grinius L, Krulwich TA, Girvin ME. An evaluation of detergents for NMR structural studies of membrane proteins. J. Biomol. NMR 2004;28:43-57. [PubMed: 14739638]

61. Tian C, Breyer RM, Kim HJ, Karra MD, Friedman DB, Karpay A, Sanders CR. Solution NMR spectroscopy of the human vasopressin V2 receptor, a G protein-coupled receptor. J. Am. Chem. Soc 2005;127:8010-8011. [PubMed: 15926814]

62. Tian C, Breyer RM, Kim HJ, Karra MD, Friedman DB, Karpay A, Sanders CR. Solution NMR spectroscopy of the human vasopressin v2 receptor, a g protein-coupled receptor [j. Am. Chem. Soc. 2005, 127, 8010-8011]. J. Am. Chem. Soc 2006;128:5300.

63. Aiyar N, Nambi P, Stassen F, Crooke ST. Solubilization and reconstitution of vasopressin V1 receptors of rat liver. Mol. Pharmacol 1987;32:34-36. [PubMed: 2955212]

64. Aiyar N, Bennett CF, Nambi P, Valinski W, Angioli M, Minnich M, Crooke ST. Solubilization of rat liver vasopressin receptors as a complex with a guanine-nucleotide-binding protein and phosphoinositide-specific phospholipase C. Biochem. J 1989;261:63-70. [PubMed: 2549966]

65. Aiyar N, Valinski W, Nambi P, Minnich M, Stassen FL, Crooke ST. Solubilization of a guanine nucleotide-sensitive form of vasopressin V2 receptors from porcine kidney. Arch. Biochem. Biophys 1989;268:698-706. [PubMed: 2521556]

66. Huang P, Liu Q, Scarborough GA. Lysophosphatidylglycerol: a novel effective detergent for solubilizing and purifying the cystic fibrosis transmembrane conductance regulator. Anal. Biochem 1998;259:89-97. [PubMed: 9606148]

67. Williams KA, Farrow NA, Deber CM, Kay LE. Structure and dynamics of bacteriophage IKe major coat protein in MPG micelles by solution NMR. Biochemistry 1996;35:5145-5157. [PubMed: 8611498]

68. Pervushin K, Riek R, Wider G, Wuthrich K. Attenuated T2 relaxation by mutual cancellation of dipole-dipole coupling and chemical shift anisotropy indicates an avenue to NMR structures of very large biological macromolecules in solution. Proc. Natl. Acad. Sci. U. S. A 1997;94:12366-12371. [PubMed: 9356455]

69. Furukawa T, Ono Y, Tsuchiya H, Katayama Y, Bang ML, Labeit D, Labeit S, Inagaki N, Gregorio CC. Specific interaction of the potassium channel beta-subunit minK with the sarcomeric protein Tcap suggests a T-tubule-myofibril linking system. J. Mol. Biol 2001;313:775-784. [PubMed: 11697903]

70. Chandrasekhar KD, Bas T, Kobertz WR. KCNE1 subunits require co-assembly with K+ channels for efficient trafficking and cell surface expression. J. Biol. Chem 2006;281:40015-40023. [PubMed: 17065152]

71. Krumerman A, Gao X, Bian JS, Melman YF, Kagan A, McDonald TV. An LQT mutant minK alters KvLQT1 trafficking. Am. J. Physiol Cell Physiol 2004;286:C1453-C1463. [PubMed: 14761891] 


\section{Supplementary Material}

Refer to Web version on PubMed Central for supplementary material. 


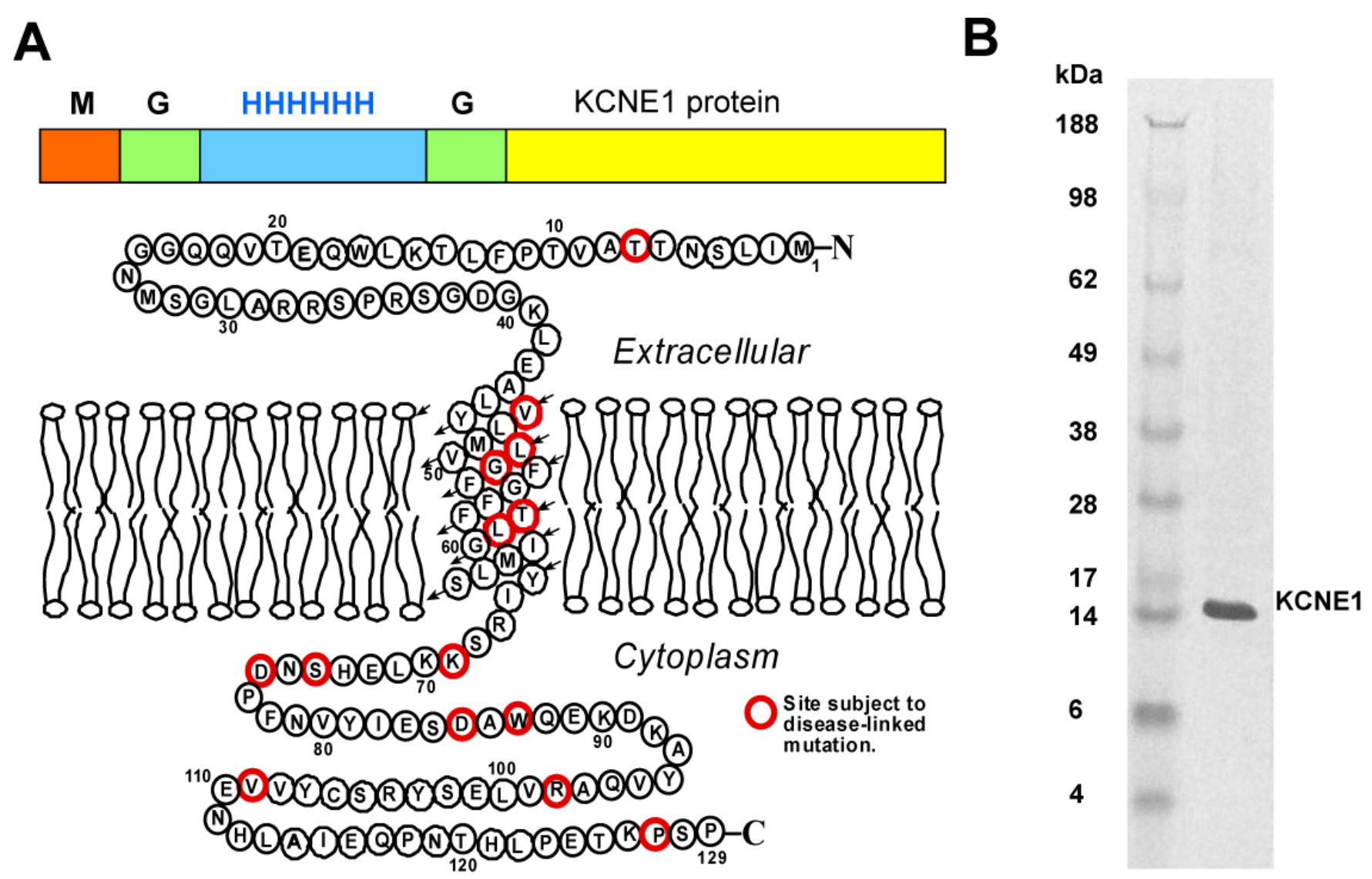

Figure 1.

(A) Top: Construction of tagged KCNE1 that was used in this study. Bottom: Sequence and predicted membrane topology of full length untagged wild type human KCNE1 (Gene Bank accession \# L28168). The small arrows shown for the TM segment show the tracing of the peptide chain. Nothing is implied by this panel regarding the conformation of the protein. (B) SDS-PAGE with coomassie staining following expression and purification of $\mathrm{His}_{6}$-KCNE1 into LMPG micelles. The mobility of the His $_{6}-\mathrm{KCNE} 1$ in the SDS-PAGE gel is compatible with its molecular weight $(15.7 \mathrm{kDa})$. The identity of this band as tagged KCNE1 was confirmed by mass spectrometry. 
A

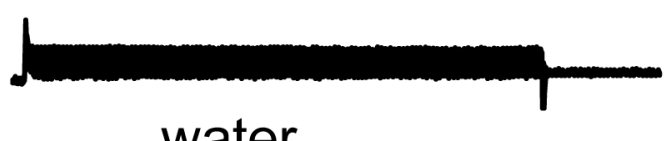

water

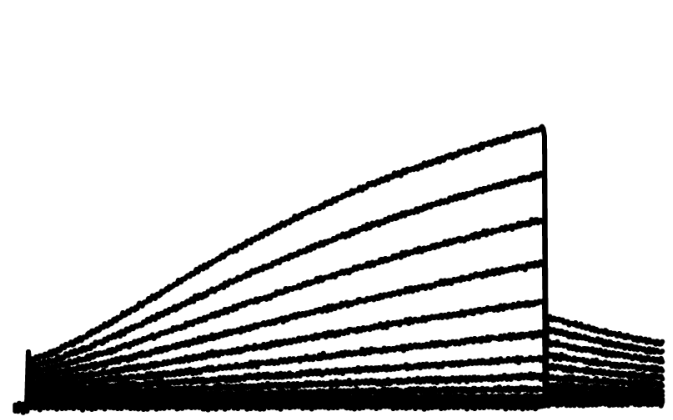

KCNQ1 + KCNE1

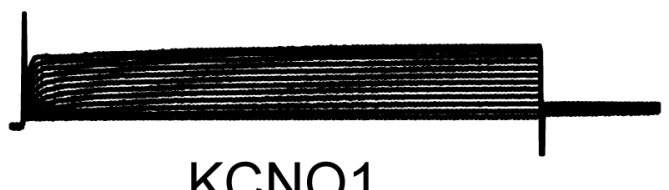

$500 \mathrm{~ms}$

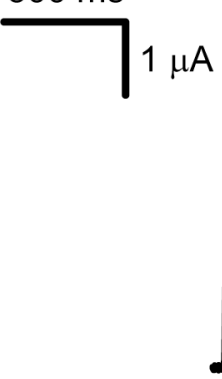

KCNQ1 + His-KCNE1
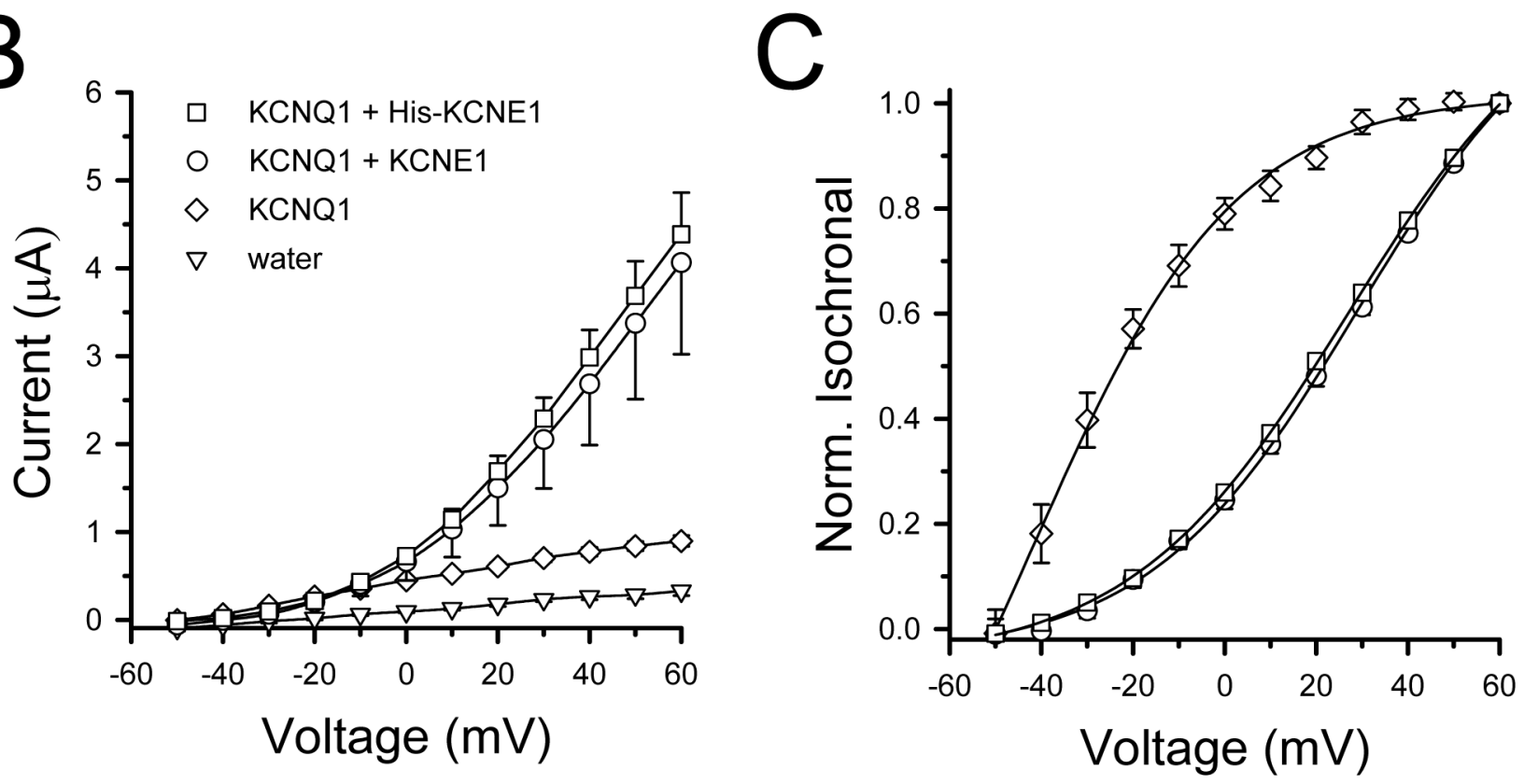

Figure 2.

Functional expression of His $_{6}$-KCNE1 in Xenopus oocytes. (A) Representative current traces recorded from oocytes injected with either water $(\mathrm{N}=9)$, cRNA for KCNQ1 only $(\mathrm{N}=12)$, cRNA for both KCNQ1 and untagged KCNE1 $(\mathrm{N}=8)$, or cRNA for both KCNQ1 and His $6^{-}$ KCNE1 $(\mathrm{N}=10)$. (B) Current-voltage relationship for currents measured after 2 sec test pulses from a holding potential of $-80 \mathrm{mV}$. (C) Normalized isochronal activation curves for oocytes injected with either water or cRNA. Data were fit with a Boltzmann function. 
$\begin{array}{llll}\text { A DPC } & \text { B }\end{array}$

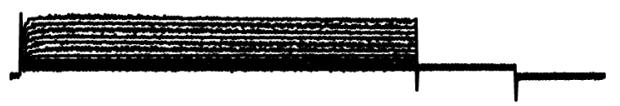

C PMAL-C12

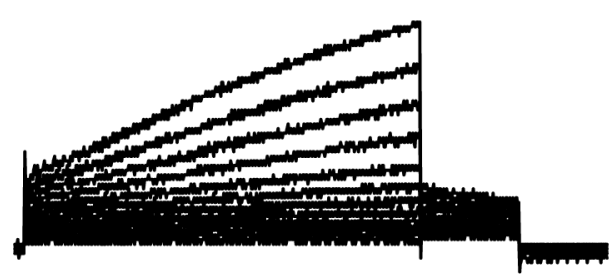

E LMPC/G

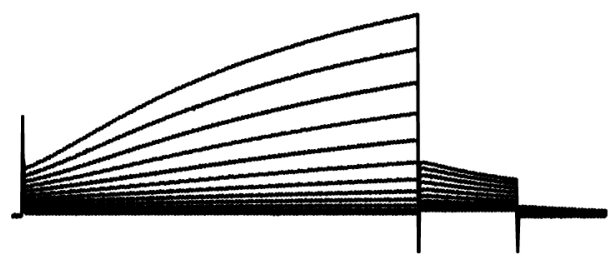

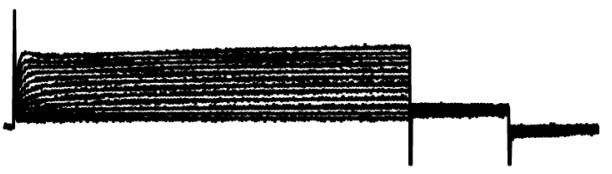

D DTAB

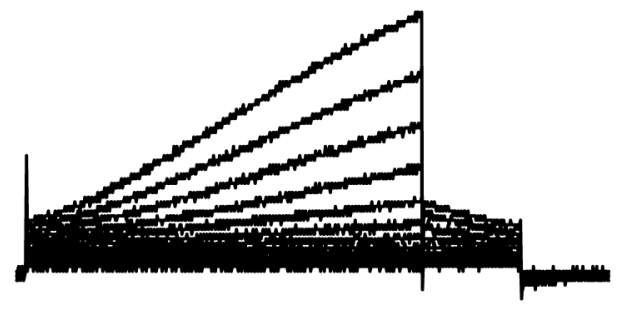

F LMPG

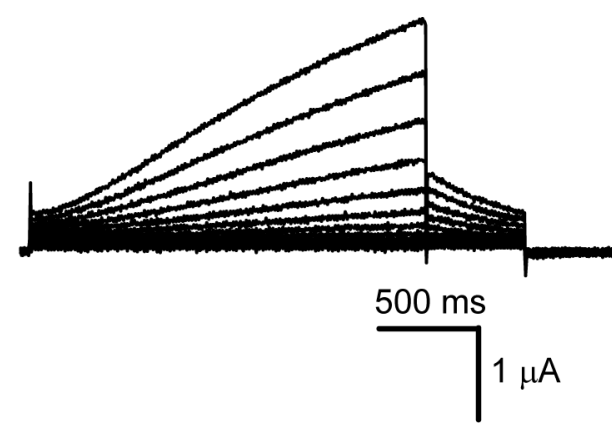

Figure 3.

Representative current traces recorded from oocytes injected with cRNA for KCNQ1 plus purified recombinant $\mathrm{His}_{6}-\mathrm{KCNE}_{1}$ protein in different detergents: (A) DPC (N=8), (B) SDS, $\mathrm{N}=$ 9, (C) PMAL-C12 (N=5), (D) DTAB (N=6), (E) LMPC/LMPG (4:1 molar ratio, N=7), and $(\mathbf{F})$ LMPG $(\mathrm{N}=9)$. 
A
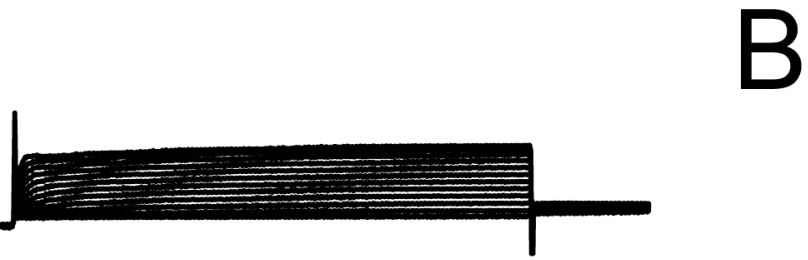

KCNQ1

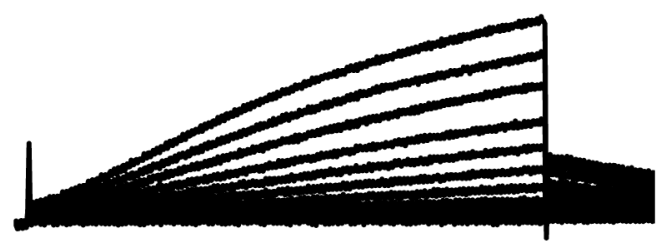

KCNQ1 + His-KCNE1

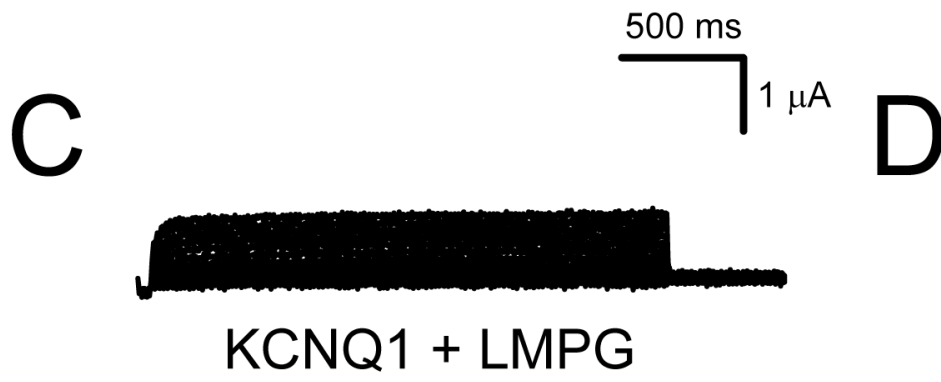

KCNQ1 + His-KCNE1/LMPG

$E$
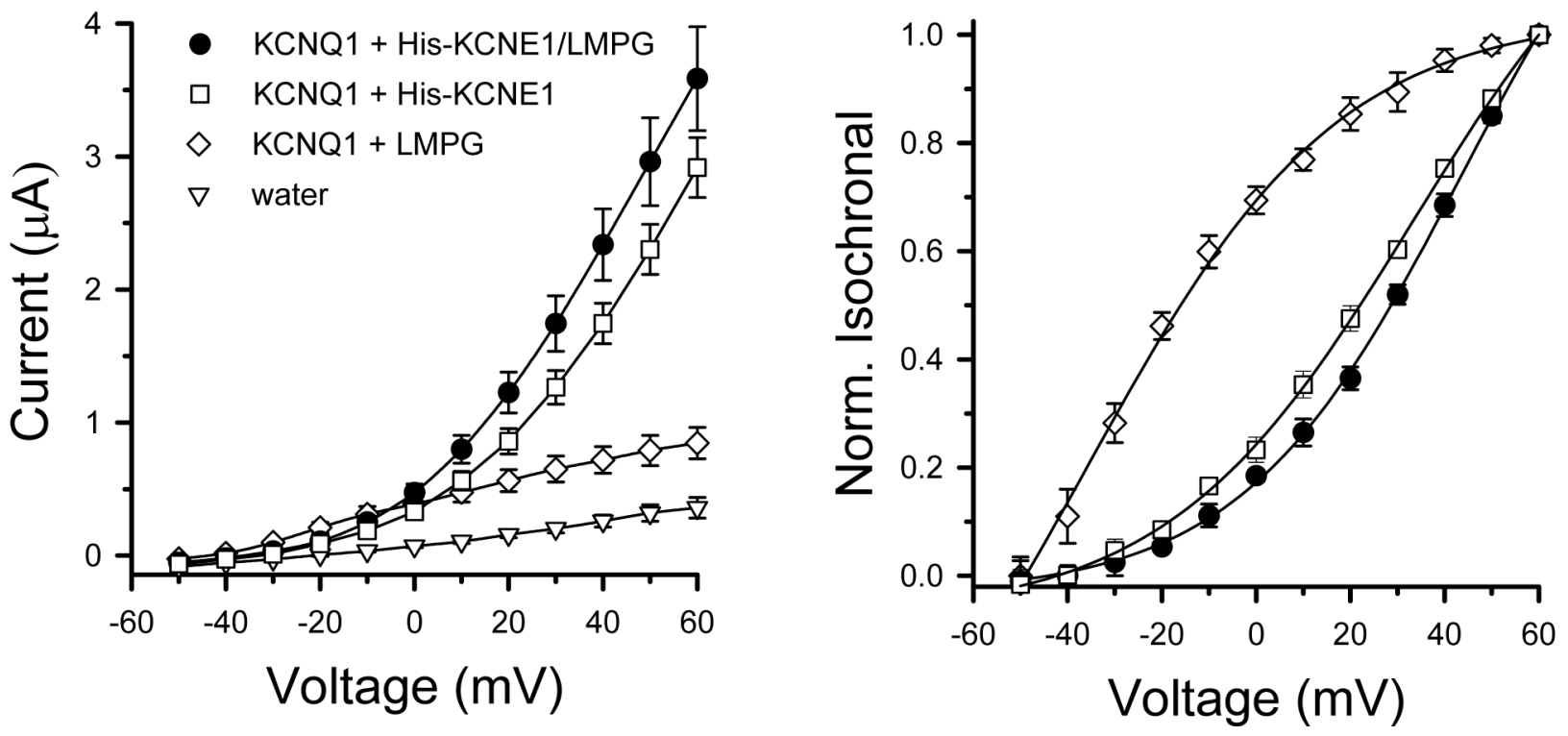

Figure 4.

Modulation of KCNQ1 channels in Xenopus oocytes. Representative current traces recorded from oocytes injected with (A) cRNA for KCNQ1 only $(\mathrm{N}=6),(\mathbf{B})$ cRNA for both KCNQ1 and $\mathrm{His}_{6}{ }^{-\mathrm{KCNE} 1}(\mathrm{~N}=11),(\mathbf{C})$ cRNA for KCNQ1 plus LMPG micelles (no KCNE1, N= 17), and (D) cRNA for KCNQ1 plus purified $\mathrm{His}_{6} \mathrm{KCNE}^{\mathrm{K}}$ in LMPG micelles $(\mathrm{N}=10)$. Oocytes were injected with cRNAs or water, followed 24 hours later by injection with either "empty" or $\mathrm{His}_{6}$-KCNE1-containing 0.1\% LMPG micelles. Currents were then recorded 24 hours after the second injection. (E) Current-voltage relationship measured after 2 s pulses from oocytes that were injected either with water $(\mathrm{N}=13)$, cRNA for KCNQ1 plus LMPG micelles (no $\mathrm{KCNE} 1$ ), cRNA for both KCNQ1 and $\mathrm{His}_{6}-\mathrm{KCNE} 1$, or cRNA for KCNQ1 plus purified His $_{6}$-KCNE1 in LMPG micelles. (F) Normalized isochronal activation curves for oocytes injected with cRNA for KCNQ1 plus LMPG micelles (no KCNE1), cRNA for both KCNQ1 
and $\mathrm{His}_{6}$-KCNE1, or cRNA for KCNQ1 plus purified His $_{6}$-KCNE1 in LMPG micelles. Fit of these data with Boltzman distributions resulted in the following fit parameters; cRNA KCNQ1 plus LMPG micelles (no KCNE1): $\mathrm{V}_{1 / 2}=-34.3 \pm 3.2$ and $k_{V}=20.9 \pm 2.2$; cRNA for both KCNQ1 and His $_{6}-\mathrm{KCNE} 1: \mathrm{V}_{1 / 2}=28.5 \pm 0.7$ and $k_{V}=20.6 \pm 0.6$; cRNA for KCNQ1 plus purified $\mathrm{His}_{6}$-KCNE1 in LMPG micelles: $\mathrm{V}_{1 / 2}=32.1 \pm 1.7$ and $k_{V}=23.5 \pm 1.1$. 

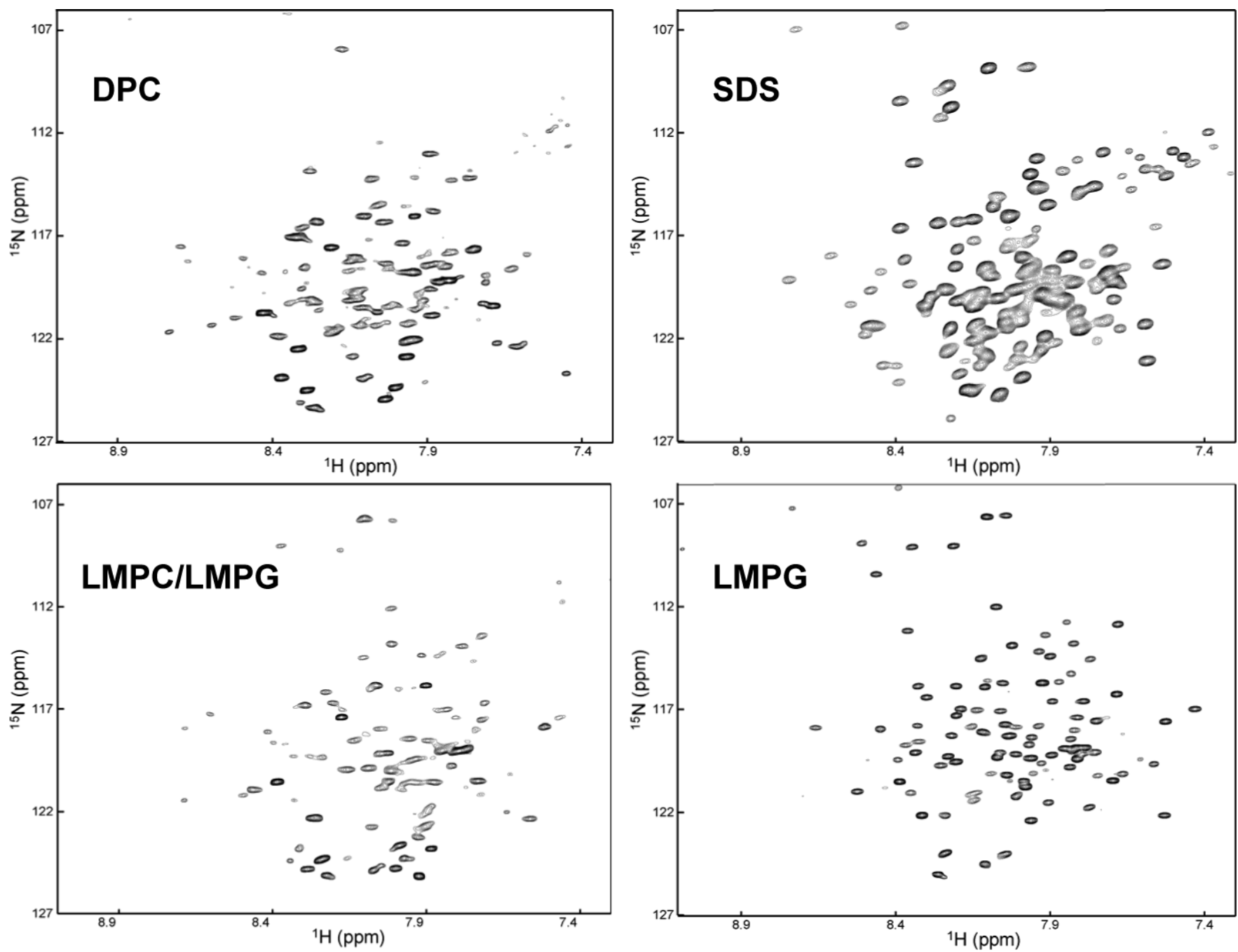

Figure 5.

2-D $600 \mathrm{MHz}^{1} \mathrm{H}_{-}{ }^{15} \mathrm{~N}$ TROSY NMR spectra of purified $\mathrm{U}_{-}{ }^{15} \mathrm{~N}-\mathrm{His}_{6}-\mathrm{KCNE} 1$ at $1-1.5 \mathrm{mM}$ in different detergent micelles. Samples contained $250 \mathrm{mM}$ imidazole, $2 \mathrm{mM}$ DTT, and $2 \mathrm{mM}$ EDTA, pH 6.0. All the spectra were acquired with $256 \times 1024$ complex points (prior to zerofilling) at $40^{\circ} \mathrm{C}$. Data were processed using zero-filling and Gaussian apodization in both dimensions (the same parameters were used in processing all 4 spectra). The concentrations of detergents were as follows: (A) $300 \mathrm{mM}$ DPC, (B) $300 \mathrm{mM}$ SDS, (C) $150 \mathrm{mM} \mathrm{LMPC/}$ LMPG (4:1 molar ratio), and (D) $150 \mathrm{mM}$ LMPG. It should be noted that the linewidths for most peaks in the SDS case are similar to those of LMPG. However, the SDS spectrum has been plotted at a higher scale than LMPG (leading to the mistaken impression of broader peaks) so as to allow observation of a few weak peaks that would not be observed if the SDS spectrum was plotted at the same scale as the LMPG case. An additional spectrum (not shown) acquired for KCNE1 in $300 \mathrm{mM}$ DPC/SDS (10:1) closely resembled that of DPC alone (panel A). Overlays of the spectra for SDS, DPC, and LMPC/LMPG with the assigned spectrum for LMPG are provided as Supporting Figure 1. 


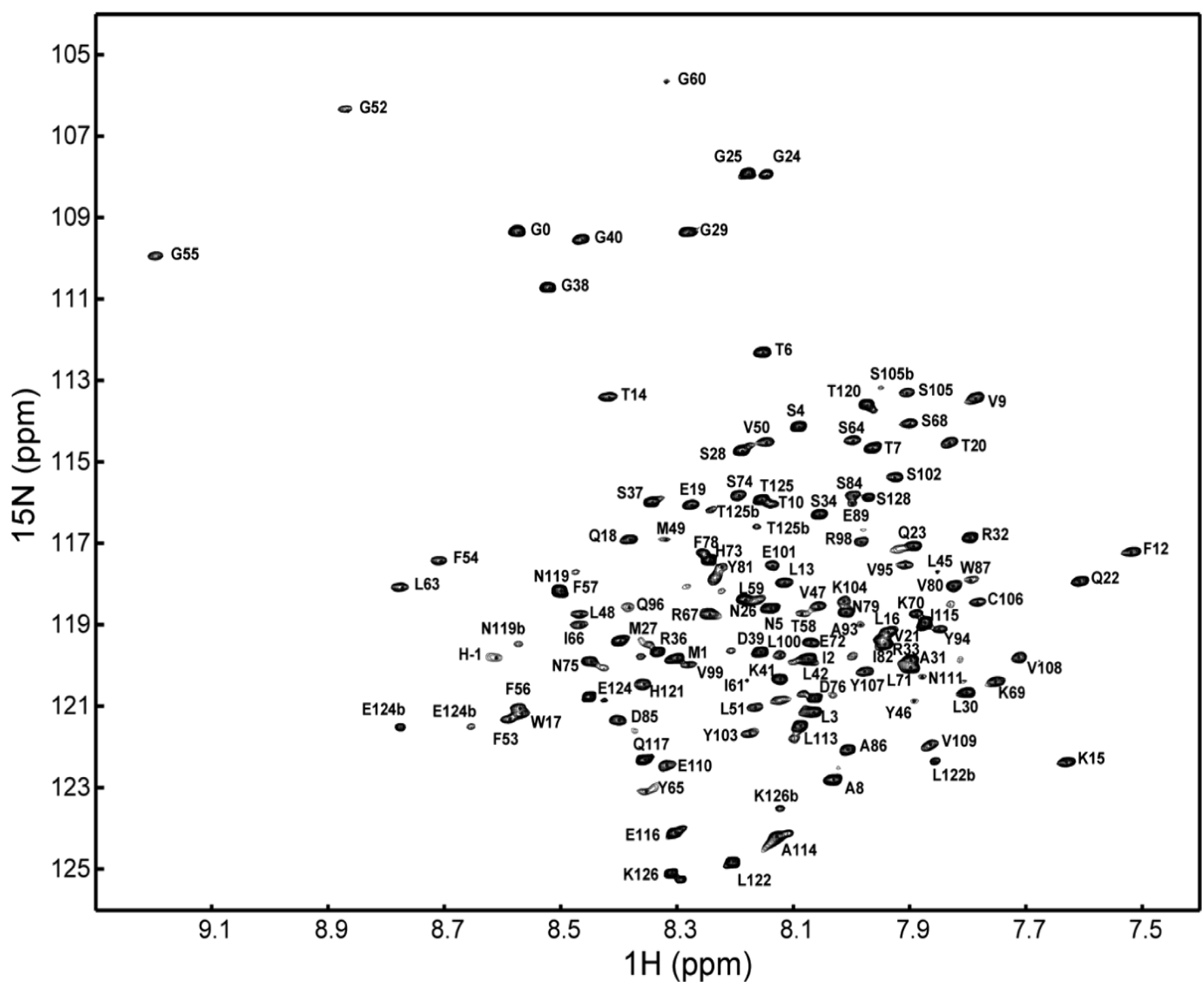

Figure 6.

${ }^{1} \mathrm{H}-{ }^{15} \mathrm{~N}$ TROSY spectrum of uniformly- ${ }^{2} \mathrm{H},{ }^{13} \mathrm{C},{ }^{15} \mathrm{~N}$-labeled KCNE1 in 4\% LMPG, 10\% D2O, $250 \mathrm{mM}$ imidazole/acetic acid, $2 \mathrm{mM}$ DTT, and $2 \mathrm{mM}$ EDTA, pH 6.0. The spectrum was recorded at $40^{\circ} \mathrm{C}$ on a $900 \mathrm{MHz}$ spectrometer with 256 complex points in t1, 1024 complex points in $\mathrm{t} 2$, and 4 scans per increment. Backbone amide resonance assignments are indicated by the one-letter amino acid code and the sequence number. The cross peaks for 119b, 122b, $124 \mathrm{~b}, 125 \mathrm{~b}, 126 \mathrm{~b}$ represent the presence of second conformation that is spectroscopically detectable for those residues as a result of cis/trans isomerization for the neighboring Pro residues (Pro118, Pro123 and Pro127) in the flexible distal C-terminus. The cross peaks for His $(-1)$ and Gly0 represent the residues linking the N-terminal purification tag to the first residue (Met1) of KCNE1 proper. The assignment for site 93 remains tentative. 

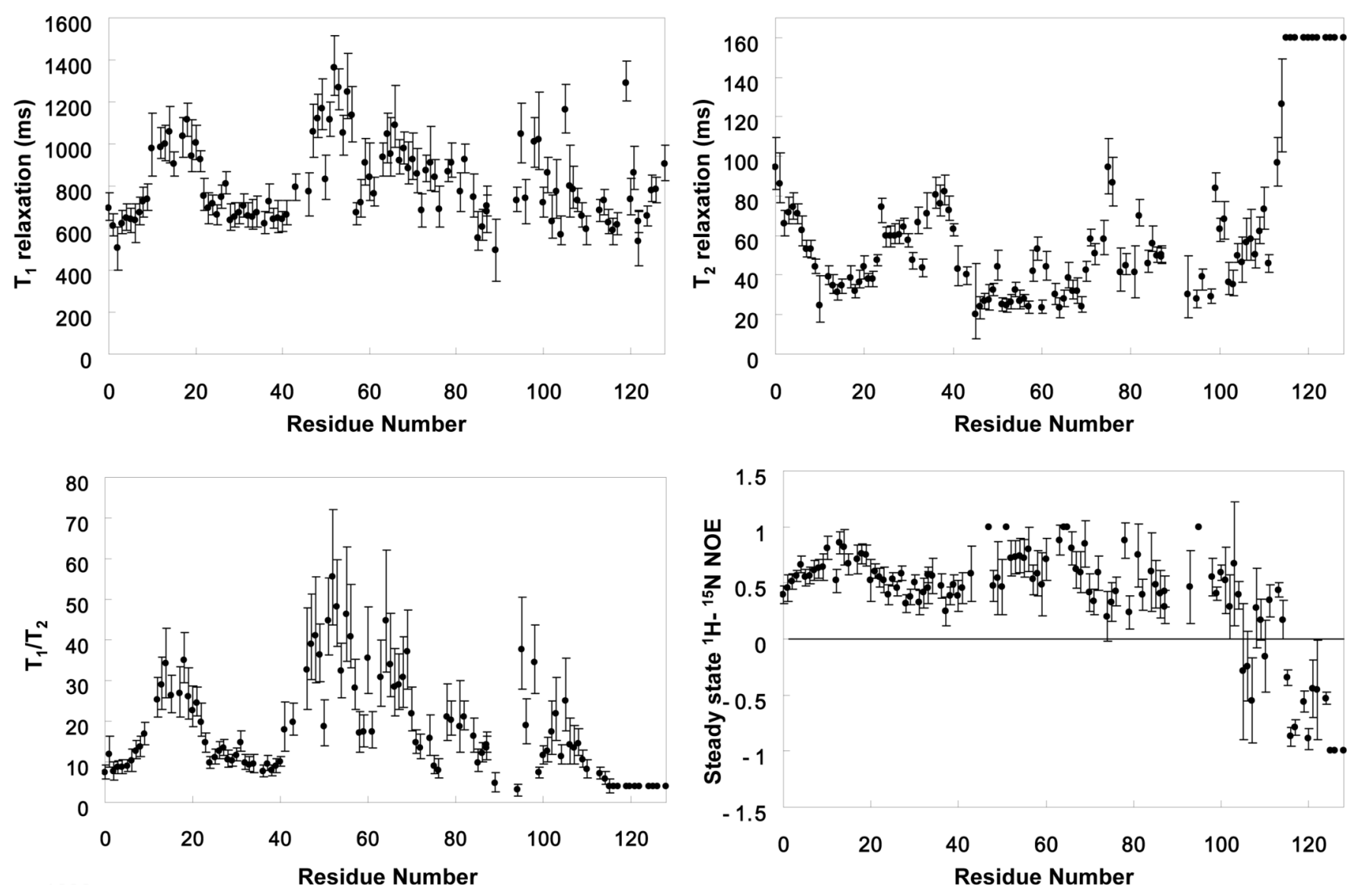

Figure 7.

$600 \mathrm{MHz}$ NMR relaxation parameters for $\mathrm{His}_{6}-\mathrm{KCNE} 1$ in LMPG micelles at $40^{\circ} \mathrm{C}$. Values reported with no error bars represent measurements for which only lower boundary $\left(\mathrm{T}_{2}\right)$ or upper boundary $\left(\mathrm{T}_{1} / \mathrm{T}_{2}\right.$, $\left.|\mathrm{NOE}|\right)$ values could be determined. Sites for which no values are reported represent residues for which assignments were not available or for which extensive resonance overlap hindered the extraction of reliable parameters. The corresponding data at $800 \mathrm{MHz}$ is provided in Supporting Figure 2. 